\title{
Review \\ Biogenic Silver Nanoparticles: What We Know and What Do We Need to Know?
}

\author{
Mahendra Rai ${ }^{1,2, * \mathbb{C}}$, Avinash P. Ingle ${ }^{3}$, Joanna Trzcińska-Wencel ${ }^{1}{ }^{\mathbb{C}}$, Magdalena Wypij ${ }^{1}$, Shital Bonde ${ }^{2}$, \\ Alka Yadav ${ }^{2}$, Gabriela Kratošová ${ }^{4(\text { (D) }}$ and Patrycja Golińska ${ }^{1, *(1)}$
}

Citation: Rai, M.; Ingle, A.P.; Trzcińska-Wencel, J.; Wypij, M.; Bonde, S.; Yadav, A.; Kratošová, G.; Golińska, P. Biogenic Silver Nanoparticles: What We Know and What Do We Need to Know? Nanomaterials 2021, 11, 2901. https://doi.org/10.3390/ nano11112901

Academic Editors: Josef Jampilek, Daniela Placha and Alexey Pestryakov

Received: 16 September 2021 Accepted: 27 October 2021 Published: 29 October 2021

Publisher's Note: MDPI stays neutral with regard to jurisdictional claims in published maps and institutional affiliations.

Copyright: (c) 2021 by the authors. Licensee MDPI, Basel, Switzerland. This article is an open access article distributed under the terms and conditions of the Creative Commons Attribution (CC BY) license (https:/ / creativecommons.org/licenses/by/ $4.0 /)$.
1 Faculty of Biological and Veterinary Sciences, Nicolaus Copernicus University in Toruń, Lwowska 1, 87-100 Torun, Poland; trzcinska@doktorant.umk.pl (J.T.-W.); mwypij@umk.pl (M.W.)

2 Department of Biotechnology, Sant Gadge Baba Amravati University, Amravati 444602, India; shitalbonde@gmail.com (S.B.); nanoalka@gmail.com (A.Y.)

3 Biotechnology Centre, Department of Agricultural Botany, Dr. Panjabrao Deshmukh Krishi Vidyapeeth, Akola 444104, India; ingleavinash14@gmail.com

4 Nanotechnology Centre, CEET, VŠB-Technical University of Ostrava, 17. listopadu 2172/15, 70800 Ostrava Poruba, Czech Republic; gabriela.kratosova@vsb.cz

* Correspondence: mahendra.rai@v.umk.pl (M.R.); golinska@umk.pl (P.G.); Tel.: +91-779-8077-773 (M.R.); + 0048-56611-4436 (P.G.)

\begin{abstract}
Nanobiotechnology is considered to be one of the fastest emerging fields. It is still a relatively new and exciting area of research with considerable potential for development. Among the inorganic nanomaterials, biogenically synthesized silver nanoparticles (bio-AgNPs) have been frequently used due to their unique physicochemical properties that result not only from their shape and size but also from surface coatings of natural origin. These properties determine antibacterial, antifungal, antiprotozoal, anticancer, anti-inflammatory, and many more activities of bio-AgNPs. This review provides the current state of knowledge on the methods and mechanisms of biogenic synthesis of silver nanoparticles as well as their potential applications in different fields such as medicine, food, agriculture, and industries.
\end{abstract}

Keywords: silver nanoparticles; biosynthesis; application; biodistribution; toxicity

\section{Introduction}

Nanotechnology is emerging as a science of the 21st century that has attracted a great deal of attention from the global scientific community due to its pathbreaking innovations and applications in varied sectors [1]. Nanomaterials are considered to be the building blocks of nanotechnology and are found to possess various unique properties, such as optical, mechanical, catalytic, and biological properties, etc., that make them the materials of choice for nanotechnologists. In addition, features such as the extremely small size of nanomaterials, their high surface area-to-volume ratio, high reactivity, and compatibility, etc., enhance their suitability for various purposes, including biomedical applications [2]. To date, different physical, chemical, and biological approaches have been proposed for the synthesis of nanoparticles. Among these approaches, physical and chemical approaches are reported to have control on the size of synthesized nanoparticles, but they have their own shortcomings. As far as physical synthesis is concerned, it involves usage of radiation (e.g., microwave, UV light, etc.), high temperature, and pressure, which might be hazardous. Moreover, in the case of chemical synthesis, usage of toxic chemicals is the main drawback. Considering these issues, the demand for a newer, novel, and ecofriendly synthesis approach was raised, and that search has been fulfilled with the option of biological synthesis of nanoparticles [3-6].

Recently, the green synthesis of nanomaterials has garnered the attention of nanotechnologists and has given birth to a new branch known as "green nanotechnology" [7]. The biosynthesis of AgNPs is considered to be a green route as it follows the principles of green 
chemistry and is the basis of sustainable development. It is usually performed by using various microorganisms such as fungi, bacteria, green algae, and also plants. Biosynthesis has several advantages over the physical and chemical processes because it is eco-friendly, cost-effective, and can be executed at ambient temperature and pressure, with enhanced bioactivity, and less toxicity. It was demonstrated that the proteins and enzymes secreted by the above-mentioned bio-systems act as reducing agents that reduce the bulk metal salt into respective nanoparticles and also act as capping agents that provide stability to nanoparticles and make them bio-compatible for various biological applications [8,9]. Among the metal nanoparticles, silver nanoparticles (AgNPs) have been revealed to have an enormous number of applications, particularly in biomedicine due to their broad range of antimicrobial potential, including antibacterial, antifungal, antiviral, and antiprotozoal properties $[10,11]$. Therefore, special focus has been given to biogenic AgNPs.

In this review, we discuss different methods of synthesis of AgNPs, with special reference to bio-inspired synthesis and purification of nanoparticles. The different views on the mechanism involved in biosynthesis provide insights into how AgNPs are synthesized by biological systems. We also elaborate the applications of AgNPs in medicine, agriculture, textiles, sensors, etc. The biodistribution and toxicity of biogenically synthesized AgNPs are also discussed.

\section{Biosynthesis Is a Solely Green and Sustainable Technology for AgNPs Synthesis}

Metal nanoparticles are well known for their unique physical, chemical, and biological properties, which depend on their size, shape, and surface charge [12,13]. The morphology and dispersity of metal nanoparticles depend on the mode of their synthesis [14]. Mostly the synthesis of nanoparticles is based on physical and chemical methods; however, the current studies in this field has raised concerns regarding the possible risks and the related effects of nanoparticles on the environment and humans [15]. Due to the growing application of nanoparticles in almost every field of science and technology, researchers have emphasized the biological synthesis of metal nanoparticles [14]. Among the different nanoparticles studied to date, AgNPs have achieved a significant place due to their excellent antimicrobial property against a broad range of pathogenic micro-organisms [16].

The biosynthesis of AgNPs using bacteria, fungi, yeasts, algae, and plants has garnered much attention in the recent decade [13]. Biosynthesis is the process of utilization of plant extracts, different microbes, and enzymes for the synthesis of metal nanoparticles (Figure 1). This process offers cost-efficient, environment-friendly, and scalable fabrication of nanoparticles without the use of any toxic chemicals [12]. Furthermore, the synthesis process can be sub-divided into two types i.e., a top-down and a bottom-up approach $[15,16]$.

\subsection{Strategies for Synthesis}

AgNPs are synthesized using physical, chemical, and biological methods. The chemical synthesis of AgNPs is achieved through chemical reduction, the electrochemical method, irradiation, and pyrolysis [15]. For the chemical synthesis process, reducing and stabilizing agents are required. Generally ascorbic acid, ethanol, borohydride, sodium citrate, etc. are used as a reducing agents [14]. During the chemical and physical synthesis use of hazardous chemicals, the high temperature and pressure needed to perform the synthesis of nanoparticles are a matter of great environmental concern [16]. Table 1 summarizes important physical, chemical, and photochemical methods commonly used for the synthesis of AgNPs. Based on the aforementioned problems of chemical and physical synthesis methods, biological synthesis appears to be the most acceptable method in terms of environmental impact. Biological synthesis involves the fabrication of AgNPs using micro-organisms or plant extract, which signifies an environmentally friendly approach towards the synthesis of metal nanoparticles. It also shows several advantages over the chemical and physical methods because of its simple, cost-efficient, high-yielding nature [15]. Biological synthesis can further be sub-divided into extracellular synthesis and intracellular synthesis. In the 
intracellular synthesis method, nanoparticles are synthesized inside the cells while, in extracellular synthesis, cell-free fungal extract is used (Figure 2).

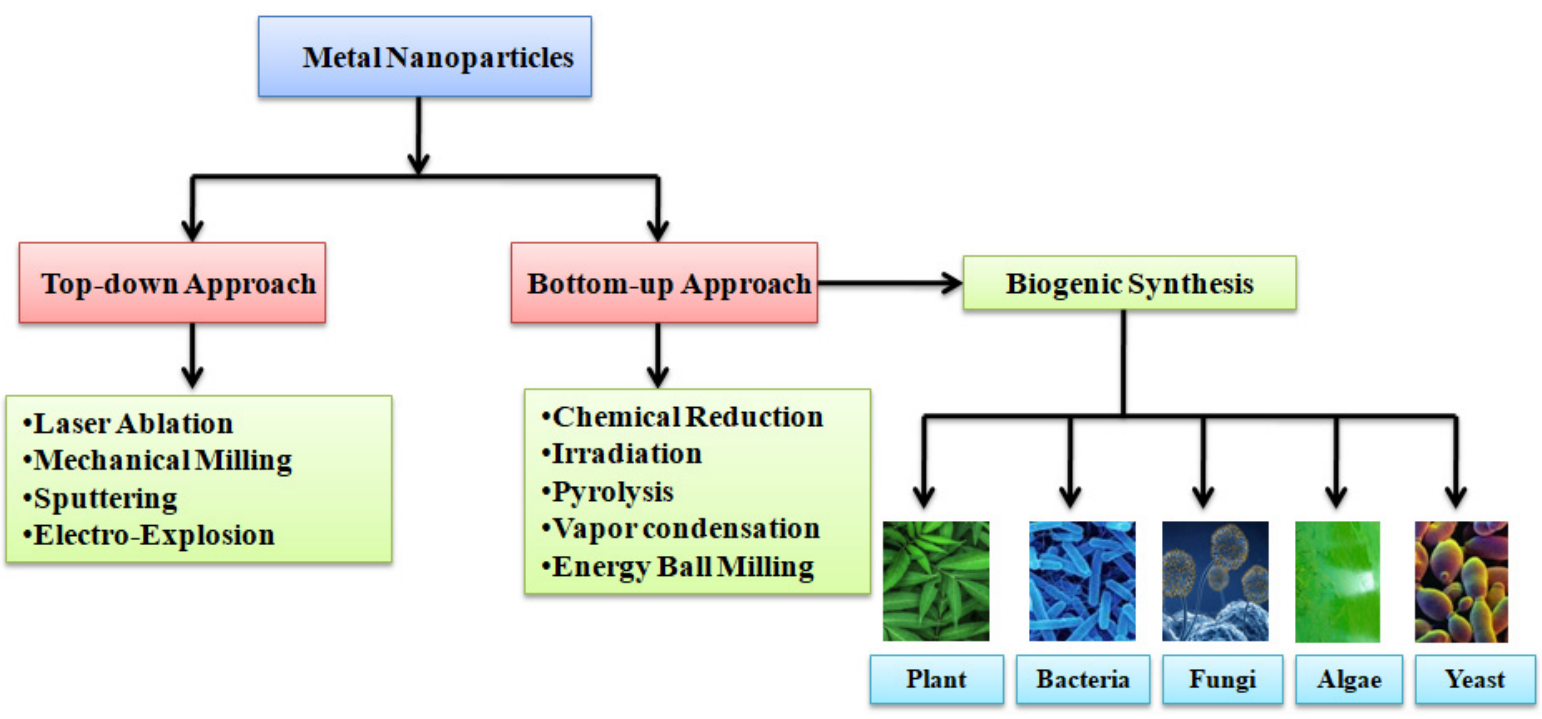

Figure 1. Synthesis of metal nanoparticles.

Table 1. Important physical, chemical, and photochemical methods used for the synthesis and stabilization of AgNPs [15].

\begin{tabular}{|c|c|c|c|c|}
\hline Method & Precursor & Reducing Agent & Stabilizing Agent & Size (nm) \\
\hline \multicolumn{5}{|c|}{ Chemical Methods } \\
\hline Chemical reduction & $\mathrm{AgNO}_{3}$ & $\begin{array}{c}\mathrm{N}, \mathrm{N}^{\prime}- \\
\text { dimethylformamide }\end{array}$ & - & $<25$ \\
\hline Chemical reduction & $\mathrm{AgNO}_{3}$ & Sodium borohydrate & $\begin{array}{l}\text { Surfactin (a lipopeptide } \\
\text { biosurfactant) }\end{array}$ & $3-28$ \\
\hline Chemical reduction & $\mathrm{AgNO}_{3}$ & $\begin{array}{l}\text { Trisodium citrate } \\
\text { (initial) }+ \text { SFS } \\
\text { (secondary) }\end{array}$ & Trisodium citrate & $<50$ \\
\hline Chemical reduction & $\mathrm{AgNO}_{3}$ & Trisodium citrate & Trisodium citrate & $30-60$ \\
\hline Chemical reduction & $\mathrm{AgNO}_{3}$ & Ascorbic acid & - & $200-650$ \\
\hline Chemical reduction & $\mathrm{AgNO}_{3}$ & Sodium borohydrate & Dodecanoic acid & $\sim 7$ \\
\hline Chemical reduction & $\mathrm{AgNO}_{3}$ & Paraffin & Oleylamine & $10-14$ \\
\hline $\begin{array}{l}\text { Chemical reduction } \\
\text { (thermal) }\end{array}$ & $\mathrm{AgNO}_{3}$ & Dextrose & Polyvinyl pyrrolidone & $22 \pm 4.7$ \\
\hline $\begin{array}{c}\text { Chemical reduction } \\
\text { (thermal) }\end{array}$ & $\mathrm{AgNO}_{3}$ & Hydrazine & - & $2-10$ \\
\hline $\begin{array}{l}\text { Chemical reduction } \\
\text { (oxidation of glucose) }\end{array}$ & $\mathrm{AgNO}_{3}$ & Glucose & Gluconic acid & $40-80$ \\
\hline $\begin{array}{l}\text { Chemical reduction } \\
\text { (polyol process) }\end{array}$ & $\mathrm{AgNO}_{3}$ & Ethylene glycol & Polyvinyl pyrrolidone & $5-25$ \\
\hline $\begin{array}{l}\text { Chemical reduction } \\
\text { (polyol process) }\end{array}$ & $\mathrm{AgNO}_{3}$ & Ethylene glycol & Polyvinyl pyrrolidone & $50-115$ \\
\hline $\begin{array}{l}\text { Chemical reduction } \\
\text { (microemulsion) }\end{array}$ & $\mathrm{AgNO}_{3}$ & Hydrazine hydrate & Aerosol-OT & $2-5$ \\
\hline
\end{tabular}


Table 1. Cont.

\begin{tabular}{|c|c|c|c|c|}
\hline Method & Precursor & Reducing Agent & Stabilizing Agent & Size $(\mathrm{nm})$ \\
\hline $\begin{array}{l}\text { Chemical reduction } \\
\text { (microemulsion) }\end{array}$ & $\mathrm{AgNO}_{3}$ & Hydrazine hydrate & Aerosol-OT & $<1.6$ \\
\hline $\begin{array}{l}\text { Electrochemical } \\
\text { (polyol process) }\end{array}$ & $\mathrm{AgNO}_{3}$ & $\begin{array}{l}\text { Electrolysis cathode: } \\
\text { titanium anode: } \mathrm{Pt}\end{array}$ & Polyvinyl pyrrolidone & $\sim 11$ \\
\hline Chemical reduction (Tollen) & $\mathrm{AgNO}_{3}$ & $\begin{array}{l}\text { m-Hydroxy } \\
\text { benzaldehyde }\end{array}$ & $\begin{array}{l}\text { Sodium formaldehyde } \\
\text { sulphoxylate }\end{array}$ & $15-260$ \\
\hline \multicolumn{5}{|c|}{ Physical Methods } \\
\hline Physical synthesis & Ag wires & $\begin{array}{c}\text { Electrical arc discharge, } \\
\text { water }\end{array}$ & - & $14-27$ \\
\hline Physical synthesis & $\mathrm{AgNO}_{3}$ & Electrical arc discharge & Sodium citrate & $2-5$ \\
\hline \multicolumn{5}{|c|}{ Photochemical Methods } \\
\hline $\begin{array}{l}\text { Photochemical } \\
\text { reduction (pulse radiolysis) }\end{array}$ & $\mathrm{AgClO}_{4}$ & Ethylene glycol & - & $17-70$ \\
\hline $\begin{array}{c}\text { Photochemical } \\
\text { reduction (microwave } \\
\text { radiation) }\end{array}$ & $\mathrm{AgNO}_{3}$ & Ethylene glycol & Polyvinyl pyrrolidone & $5-10$ \\
\hline $\begin{array}{l}\text { Photochemical } \\
\text { Reduction (photoreduction) }\end{array}$ & $\mathrm{AgNO}_{3}$ & UV light & - & $4-10$ \\
\hline $\begin{array}{c}\text { Photochemical } \\
\text { reduction (X-ray radiolysis) }\end{array}$ & $\mathrm{Ag}_{2} \mathrm{SO}_{4}$ & X-Ray & - & $\sim 28$ \\
\hline $\begin{array}{l}\text { Photochemical } \\
\text { reduction (X-ray radiolysis) }\end{array}$ & $\mathrm{AgNO}_{3}$ & $\begin{array}{l}\text { Carboxymethylated } \\
\text { chitosan, UV }\end{array}$ & $\begin{array}{c}\text { Carboxymethylated } \\
\text { chitosan }\end{array}$ & $2-8$ \\
\hline
\end{tabular}

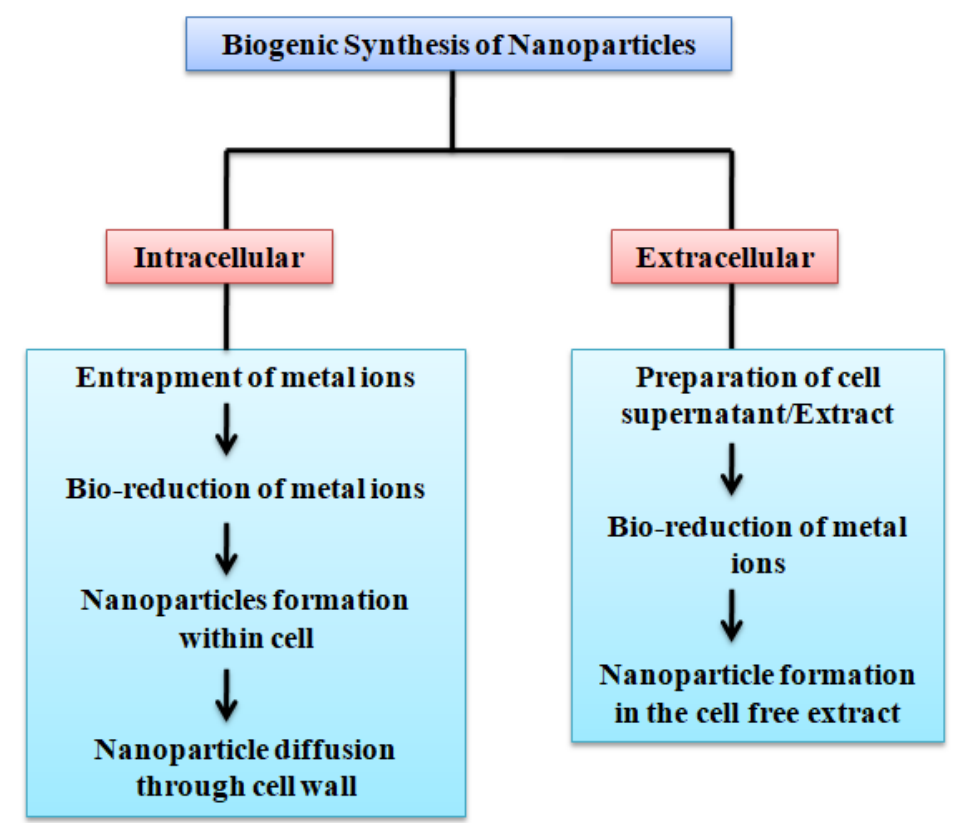

Figure 2. Methods of biosynthesis of metal nanoparticles.

\subsection{Potential Biological Agents for Eco-Friendly Synthesis of AgNPS}

Green synthesis of nanoparticles is accomplished by biological agents including bacteria, fungi, algae, yeasts, and plant extracts. It employs the use of a suitable solvent system and biological agents to achieve synthesis of nanoparticles [13]. Different microorganisms such as bacteria, fungi, yeasts, algae, and plants used for biogenic synthesis of AgNPs are 
shown in Table 2. Many bacteria such as Bacillus siamensis [17], Shewanella sp. ARY1 [18], Citrobacter freundii [19], and cyanobacteria Leptolyngbya sp. WUC 59 [20] have been used for the synthesis of AgNPs. Similarly, various fungi including Aspergillus flavus [21], Trichoderma harzianum [22], Talaromyces purpurogenus [23], and Fusarium scirpi [24] have been used for the biogenic synthesis of AgNPs. Plant extracts obtained from Protium serratum [25], Zea mays [26], Eucalyptus corymbia [27], and Lysiloma acapulsensis [28] have been recently harnessed for biogenic synthesis of AgNPs. Apart from the aforementioned bacteria, fungi, and plant species, several other biological agents have been exploited for the synthesis of AgNPs, e.g., food and agricultural wastes [29]. Figure 3 shows the TEM micrographs of AgNPs synthesized by different biological agents.

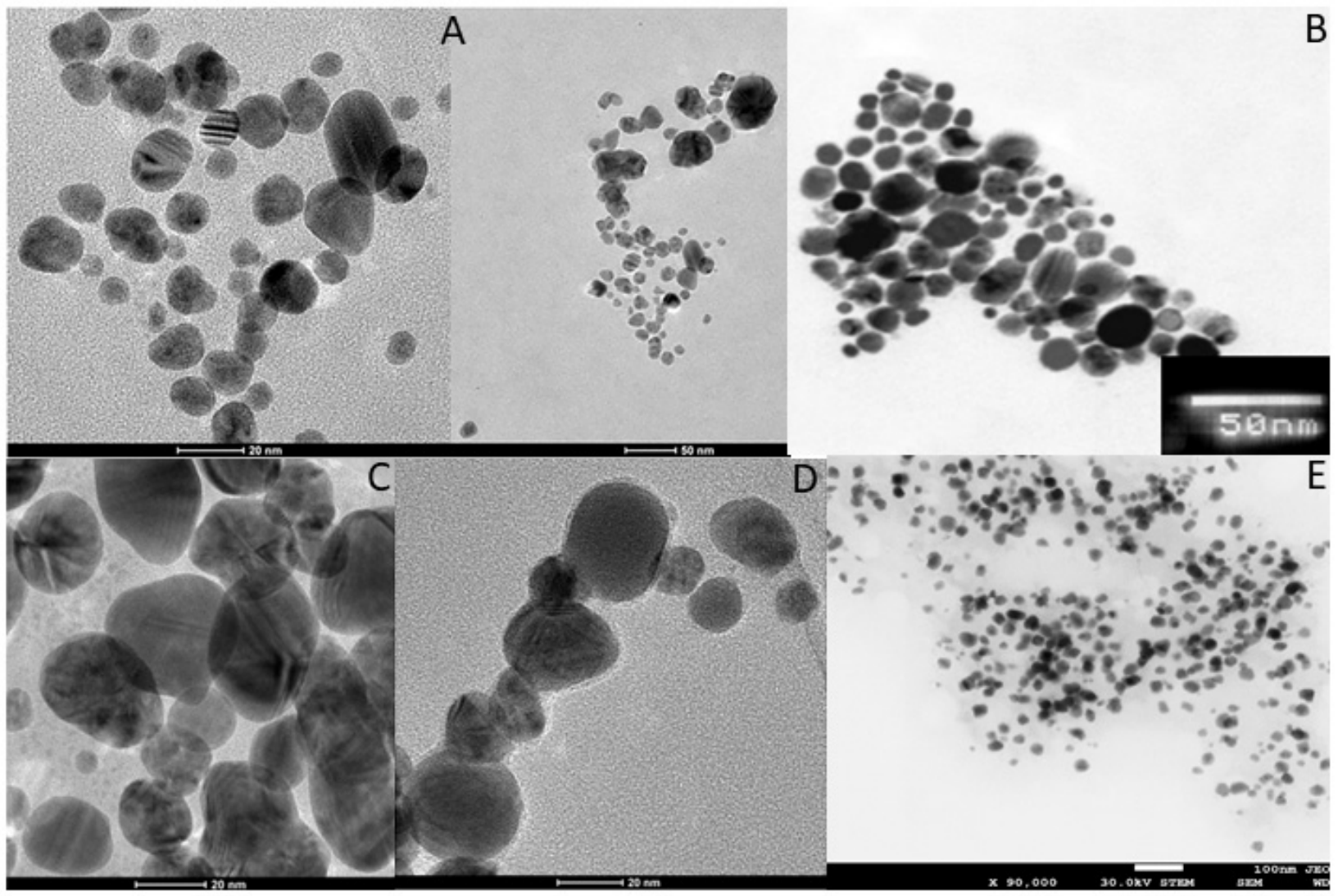

Figure 3. TEM micrographs of bio-AgNPs from (A) actinobacterial strain SF23 (adapted from [9], open access article), (B) myxobacteria, (C) Fusarium oxysporum, (D) Fusarium tricinctum, and (E) Urtica dioica.

Table 2. List of biological agents used for the synthesis of AgNPs.

\begin{tabular}{|c|c|c|c|c|c|}
\hline Biological Agent & Type & $\begin{array}{l}\text { Mode of } \\
\text { Synthesis }\end{array}$ & Size $(\mathrm{nm})$ & Shape & References \\
\hline Urospora sp. & Seaweed & Extracellular & $20-30$ & Spherical & {$[30]$} \\
\hline Aspergillus flavus & Fungus & Extracellular & 33.5 & Spherical & {$[21]$} \\
\hline Capparis spinosa & Plant & Extracellular & $5-30$ & Spherical & [31] \\
\hline Protium serratum & Plant & Extracellular & $74.56 \pm 0.46$ & Spherical & [25] \\
\hline $\begin{array}{c}\text { Trichoderma } \\
\text { longibrachiatum }\end{array}$ & Fungus & Extracellular & 10 & Spherical & [32] \\
\hline $\begin{array}{c}\text { Caesalpinia ferrera (Tul.) } \\
\text { Maritus }\end{array}$ & Plant & Extracellular & $30-50$ & Spheroidal & [33] \\
\hline Trichoderma harzianum & Fungus & Extracellular & $50-80$ & - & [22] \\
\hline Zea mays & Plant & Extracellular & 25 & Spherical & [26] \\
\hline
\end{tabular}


Table 2. Cont.

\begin{tabular}{|c|c|c|c|c|c|}
\hline Biological Agent & Type & $\begin{array}{l}\text { Mode of } \\
\text { Synthesis }\end{array}$ & Size $(\mathrm{nm})$ & Shape & References \\
\hline Torreya nucifera & Plant & Extracellular & $10-125$ & Spherical & [34] \\
\hline Bacillus siamensis & $\begin{array}{c}\text { Endophytic } \\
\text { Bacteria }\end{array}$ & Extracellular & $25-50$ & Spherical & [17] \\
\hline Aspergillus fumigatus & Fungus & Extracellular & 84.4 & $\begin{array}{l}\text { Spherical } \\
\text { Spherical, }\end{array}$ & [35] \\
\hline Talaromyces purpurogenus & Fungus & Extracellular & $4-41$ & $\begin{array}{l}\text { hexagonal, } \\
\text { rod-shaped, and } \\
\text { triangular- }\end{array}$ & [23] \\
\hline Eucalyptus corymbia & Plant & Extracellular & $18-20$ & Spherical & [27] \\
\hline Equisetum arvense & Plant & Extracellular & $18-20$ & - & [36] \\
\hline Cucumis prophetarum & Plant & Extracellular & $30-50$ & $\begin{array}{l}\text { Irregular } \\
\text { granulated, } \\
\text { ellipsoidal }\end{array}$ & [37] \\
\hline Leptolyngbya sp. WUC 59 & Cyanobacteria & Extracellular & $20-35$ & Spherical & [20] \\
\hline Lysiloma acapulsensis & Plant & Extracellular & $1.2-62$ & $\begin{array}{l}\text { Spherical and } \\
\text { quasi-spherical }\end{array}$ & [28] \\
\hline Shewanella sp. ARY1 & Bacteria & Extracellular & 38 & Spherical & [18] \\
\hline Fusarium scirpi & Fungus & Extracellular & $2-20$ & Quasi-spherical & [24] \\
\hline Synechocystis sp. & Microalgae & Extracellular & 10-100 & - & [38] \\
\hline Citrobacter freundii & Bacteria & Extracellular & $15-30$ & Spherical & [19] \\
\hline Aspergillus sydowii & Fungus & Extracellular & $1-24$ & Spherical & [39] \\
\hline
\end{tabular}

\subsection{Fungi as Promising Myconanofactories}

Mycosynthesis is used for the production of metal nanoparticles using fungi [40]. Interestingly, the fungal extracts show high tolerance to metals, and the biomass is easy to control. The biomolecules present in the fungal extracts enable easy reduction of metal ions and also ensure the stability of the nanoparticles [41]. The fungal system provides a single step biosynthesis of AgNPs and can be used for both intracellular and extracellular biosynthesis [21]. The mycelial mass of fungi can sustain a higher amount of agitation and pressure, and hence can be used for large scale biogenic synthesis [35]. The change in external parameters such as $\mathrm{pH}$, temperature, light, and amount of biomass influences the size and morphology of the AgNPs [40].

For the intracellular synthesis of AgNPs using fungi, metal salt solution is added to the fungal culture and subsequently after synthesis of AgNPs, centrifugation and filtration is accomplished to disrupt mycelial biomass and AgNPs [41], while in the extracellular synthesis of AgNPs by fungi, silver salt solution is added to the aqueous cell-free fungal filtrate, which results in simple and fast synthesis of AgNPs due to the presence of fungal enzymes. Extracellular synthesis of AgNPs using fungi has been widely followed [40]. Further, the AgNPs dispersion is purified to remove fungal contaminants through filtration, dialysis, and ultracentrifugation [21,41].

Thus, the fungal system has an advantage over the bacterial and plant system owing to the presence of a large amount of extracellular protein in the filtrate, which enables large-scale synthesis of AgNPs, and also the downstream processing of fungal biomass is much simpler compared with the other systems.

\subsection{Microfluidic Approach in Nanoparticles Biosynthesis}

Microfluidics is the science and technology of manipulating and controlling fluids, usually in the range of microliters $\left(10^{-6}\right)$ to picoliters $\left(10^{-12}\right)$, in networks of channels with the lowest dimensions from tens to hundreds of micrometers [42]. It is a multidisciplinary field that brings together physics, chemistry, engineering, biochemistry, and also nanotechnology. Microfluidic systems are preferably used in the pharmaceutical industry [43], but there are already a number of publications that demonstrate the advantages of synthesis 
of nanoparticles by microfluidics [44,45]. Generally known benefits of controlled flow synthesis on a microfluidic chip compared with batch synthesis are precise control of reaction, high conversion and selectivity, better reaction yields, flexibility, safety, uniform product quality, contamination prevention, and lower consumption of reactants. Therefore, it is not surprising that microfluidics coupled with nanotechnology begins to complement the synthesis of nanoparticles by lab-on-a-chip systems. The use of microfluidic techniques and the implementation of micro-reactors in production processes in nanotechnologies can optimize both conventional chemical and biotechnological bottom-up approaches.

Because of some issues of batch biosynthesis-typically process reproducibility and nanoparticles heterogeneity in terms of their shape and size- the scientific community is currently focusing on nanoparticles phytosynthesis using microfluidic microreactors with various channels geometry made from different materials [46,47]. The main advantage of low-cost biosynthesis, i.e., reduction and simultaneous stabilization of AgNPs, is thus enhanced by controlling the flow process. Recently, the design of reactors and their production using 3D printers has also been preferred. In general, applying microfluidics with completely different results regarding shape, size, and stability of metallic nanoparticles may be achieved, as compared to the batch synthesis. However, various process conditions must be studied to find the one that is optimal for a given plant biomass, metal precursor, and micro-reactor.

\section{Unzipping the Mechanism Involved in Biogenic Synthesis of AgNPs}

Plants, fungi, bacteria, cyanobacteria, blue-green algae, and actinomycetes are the most important biological systems used for the synthesis of AgNPs [39,48,49]. There are different mechanisms put forward by the researchers to explain the biogenic synthesis of nanoparticles based on their research outcomes [50-54]. However, the most widely studied mechanism for biosynthesis of any metal nanoparticle involves the reduction of aqueous metal ions by the donation of an electron from a particular compound or biomolecule that is present in the extracellular metabolites of the extract of the biological system. These compounds play an important role in transferring electrons to aqueous metal ions to fulfill the deficiency and reduced to their neutral form, which is commonly referred to as a nano form or nanoparticles (Figure 4). In some cases, the involvement of more than one or group of biomolecules is reported to be involved in the biosynthesis and stabilization of AgNPs. Some of the important and widely accepted mechanisms are discussed here.

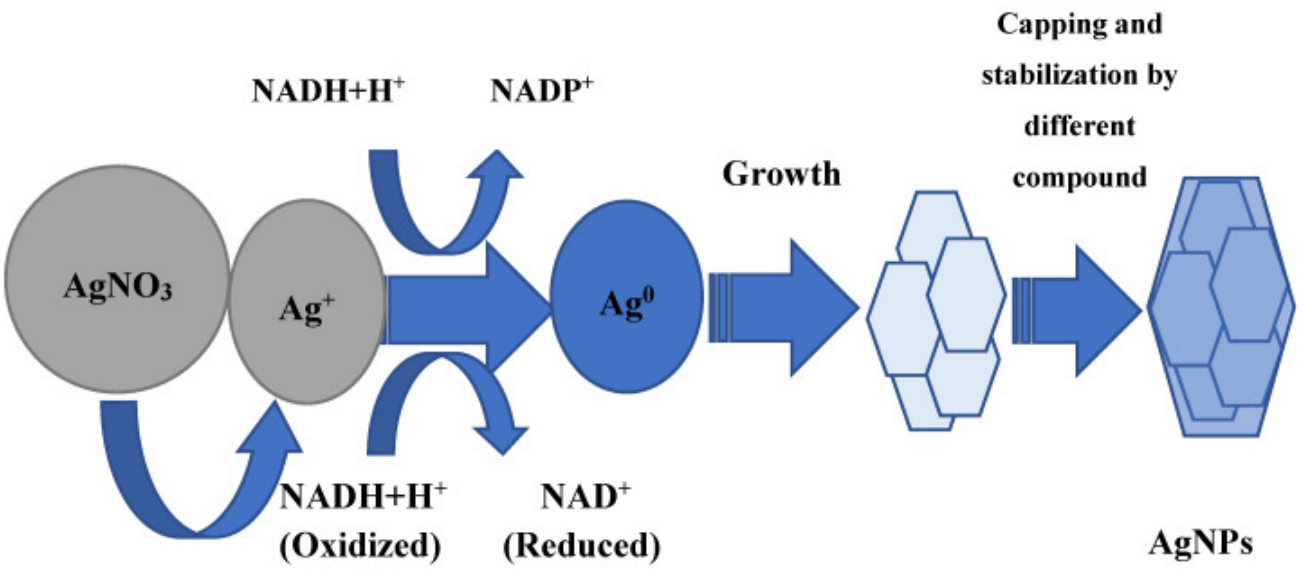

Figure 4. The general hypothetical mechanism proposed for the mycosynthesis of AgNPs (adapted from [55]; an open access article).

\subsection{Mechanism Involved in Bacterial Synthesis of AgNPs}

Different mechanisms have been suggested for the bacterial synthesis of nanoparticles. Bacteria also have potential to synthesize metal nanoparticles both intracellularly and extracellularly. The available reports suggest that extracellular synthesis of AgNPs is typical 
for both Gram-positive bacteria (e.g., Bacillus pumilus, B. persicus, B. licheniformis, B. indicus, B. cecembensis, Planomicrobium sp., Streptomyces sp., Rhodococcus sp.) and Gram-negative bacteria (e.g., Klebsiella pneumoniae, Escherichia coli and Acinetobacter calcoaceticus) [56-62]. Similarly, certain Gram-positive (e.g., Corynebacterium sp., members of the genus Streptomyces) [63] and Gram-negative bacteria such as Enterobacter and Pseudomonas stutzeri have been reported to produce AgNPs intracellularly [64,65]. As far as the mechanism in intracellular synthesis of AgNPs is concerned, it was proposed that membrane proteins are mainly responsible for the transport of silver ions into the bacterial cells, where they are reduced by enzymes and other metabolites [66]. The studies demonstrated that proteins and sugars of the cell wall (where the actual reduction process can occur) also participate in the catching of the silver ions [55].

The entrapment and transportation of silver ions in bacterial cells may be facilitated by electrostatic interaction of the positively charged silver ions and negatively charged cell wall, particularly the negatively charged carboxylate groups present on the cell wall [67]. On the other hand, different metabolites such as NADH-dependent reductase (Figure 4), sulfur-containing protein, etc. secreted by the bacteria in the surrounding medium are mainly responsible for the extracellular reduction of silver ions into AgNPs [68,69]. In addition, different amino acids viz. arginine, aspartic acid, cysteine, glutamic acid, lysine, and methionine have the capability to reduce silver ions to AgNPs [70,71]. The possible role of some peptides containing disulfide bonds was also proposed in the reduction of silver ions to AgNPs [72].

According to one of the theories, the synthesis of metal nanoparticles by bacteria is the outcome of detoxification pathways, where a variety of toxic metal ions are taken up through cationic membrane transport systems that normally transport metabolically important cations. The specialized mechanism to counteract this kind of uptake prevents excessive accumulation of toxic metals [73].

\subsection{Mechanism of Mycosynthesis of AgNPs}

Generally, it is proposed that the extracellular metabolites, including different enzymes secreted by fungi for their own survival when exposed to different environmental stresses, are responsible for the reduction of metal ions to metallic solid nanoparticles through the catalytic effect $[32,40]$. In one of the mechanisms, it was proposed that NADH-dependent nitrate reductase enzyme secreted by Fusarium oxysporum is responsible for the reduction of aqueous silver ions into AgNPs [74]. A similar mechanism was proposed by Ingle et al. [75] in the case of AgNPs synthesis from Fusarium acuminatum. The authors also pointed out the involvement of cofactor NADH and nitrate reductase enzyme in the biosynthesis of AgNPs owing to the presence of nitrate reductase in fungal cell-free extract, which was proved by using specific substrate-utilizing discs for nitrate purchased from Hi-Media Pvt. Ltd., Mumbai, India. Finally, it was proposed that nitrate reductase secreted by the biological system is responsible for the reduction of silver ions into AgNPs, and NADPH acts as cofactor and helps in transferring the charge (electron) [74,75]. NADPH is well-known for its biological role as a coenzyme, mediating charge transfer between enzymes and its natural substrate (Figure 4). However, it was demonstrated that NADPH can independently act as a reducing agent in the case of charge transfer to an inorganic compound such as metal salts. In this context, Hietzschold et al. [53] studied the role of both NADPH and nitrate reductase enzyme in the biogenic synthesis of AgNPs. This study suggests that NADPH can serve as the sole reducing agent in reducing the silver ions to AgNPs. Moreover, it was revealed that for the synthesis of AgNPs, nitrate reductase is not required. Further, it was also found that AgNPs formed in the enzyme-free reaction were smaller, monodispersed, and more stable than those synthesized with the addition of nitrate reductase. However, more studies are required to arrive at a definitive conclusion.

In another studies, Durán et al. [76] and Kumar et al. [77] proposed almost similar mechanisms for the biosynthesis of AgNPs from F. oxysporum. The former study reported the role of anthraquinones and NADPH-nitrate reductase in the biosynthesis of AgNPs. 
The electron required to fulfill the deficiency of aqueous silver ions $\left(\mathrm{Ag}^{+}\right)$and convert it into $\mathrm{Ag}$ neutral ( $\mathrm{Ag}^{0}$ i.e., $\mathrm{AgNPs}$ ) was donated by both quinone and $\mathrm{NADPH}$ (Figure 5). However, in a later study, it was demonstrated that the reduction of NADPH to NADP ${ }^{+}$and hydroxyquinoline possibly act as an electron shuttle by transferring the electron generated during the reduction of nitrate to $\mathrm{Ag}^{+}$ions and finally converting them to $\mathrm{Ag}^{0}$. Moreover, Li et al. [78] also suggested a similar mechanism in the case of the synthesis of AgNPs by using Aspergillus terreus.

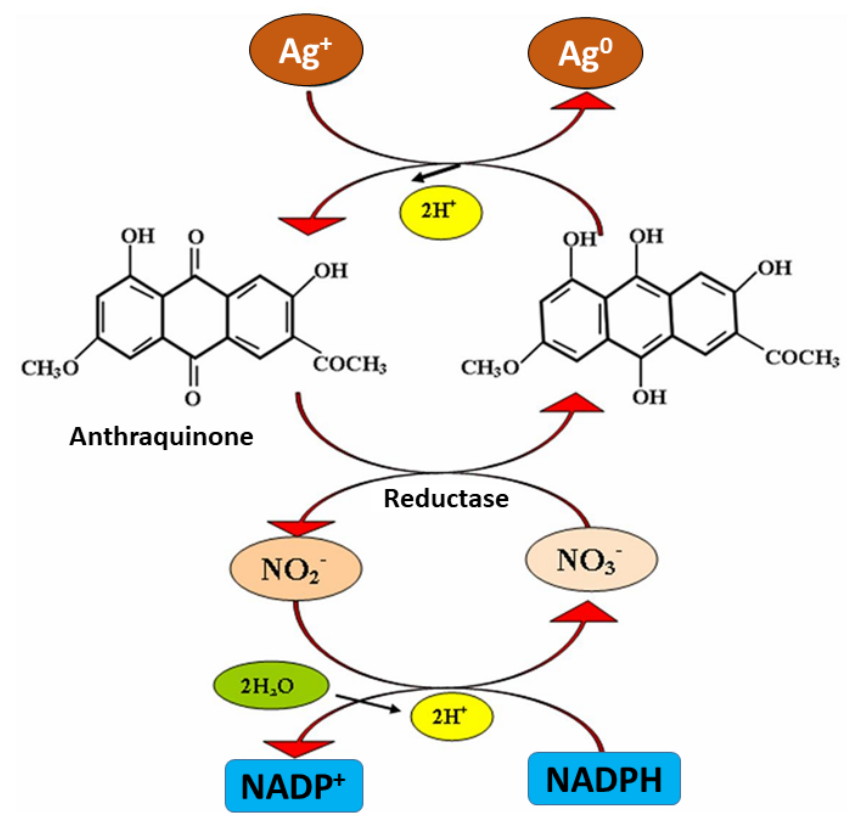

Figure 5. Possible anthraquinone-mediated hypothetical mechanisms for AgNPs synthesis (adapted and modified from [76]; an open access article).

Apart from these, the role of proteins and amino acids having -SH groups such as cysteine is also confirmed in the biosynthesis of metal nanoparticles. It is proposed that such amino acid undergoes a dehydrogenation reaction with metal salts such as silver nitrate and produces AgNPs [79]. Moreover, various amide groups (I, II, and III) are also reported to play an important role in the biosynthesis of metal nanoparticles. Sanghi and Verma [80] reported the involvement of amide I and amide II groups in the synthesis of AgNPs from Coriolus versicolor. However, in case of xylotrophic fungi, it was demonstrated that its oxidation and reduction system depends on phenol oxidase enzymes, such as $\mathrm{Mn}$ peroxidases, laccases, and tyrosinases. Therefore, it can be concluded that such enzymes may play a pivotal role in the biosynthesis of metal nanoparticles with fungal extracts [81].

As far as the intracellular synthesis of AgNPs is concerned, it was proposed that metal nanoparticles are usually synthesized below the cell surface [82], and this reduction process is mainly governed by enzymes present in the cell membrane. In intracellular mycosynthesis, initially, the entrapment of metal ions occurs due to their electrostatic interaction with lysine residues on the surface of the fungal cell [83]. Later, these metal ions are reduced through enzymatic reduction, which leads to the formation of nanoparticles. The cell-wall sugars also play a major role in the reduction of metal ions [82]. Figure 6 represents a schematic illustration of the possible mechanism involved in the intracellular mycosynthesis of AgNPs. 


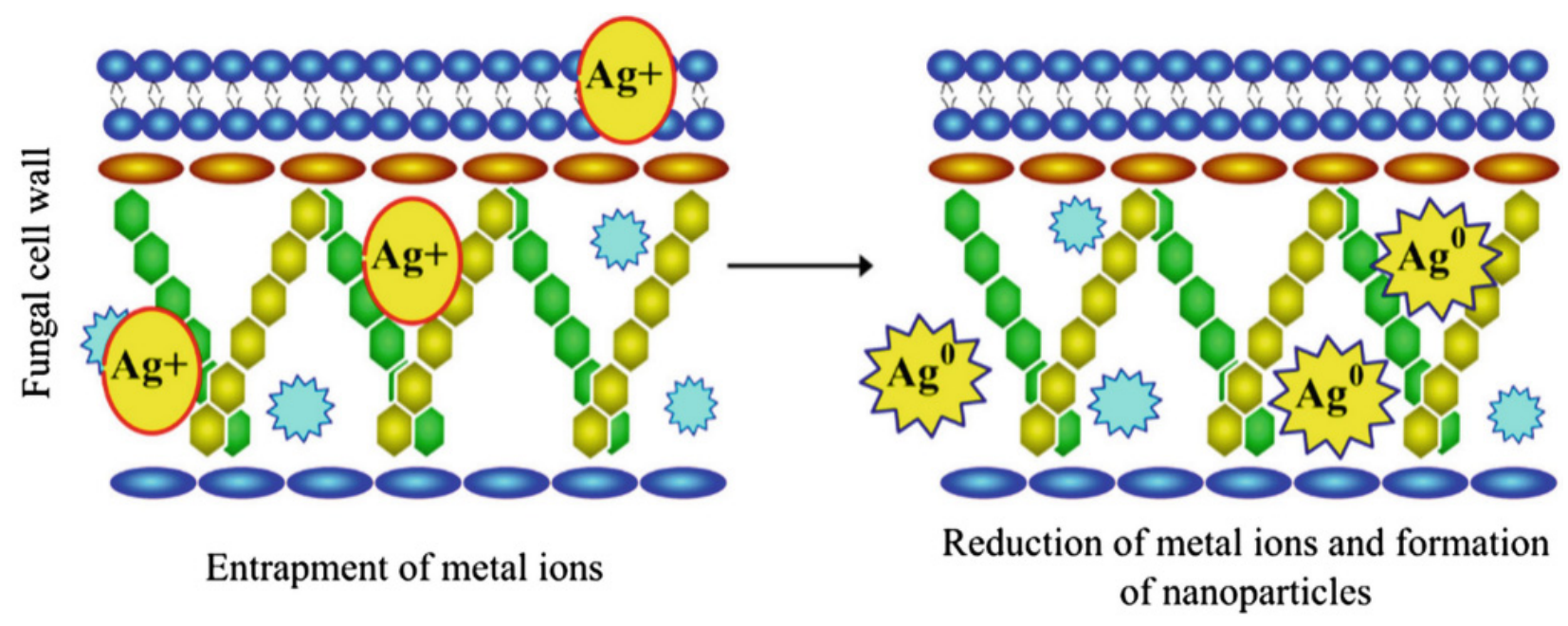

Figure 6. Possible hypothetical mechanism for intracellular mycosynthesis of AgNPs, reproduced with permission from Yadav et al. [40].

\subsection{Mechanism Involved in Phytosynthesis of AgNPs}

Several studies have been performed on the elucidation of the mechanism involved in phytosynthesis of metallic nanoparticles, and various theories have been proposed, but the actual mechanism behind the phytosynthesis of nanoparticles is still unknown [84]. However, the common hypothetical mechanism for phytosynthesis mainly involves reducing agents, stabilizing agents, and solvent medium. The phytochemicals present in the plant extract play a dual role as reducing and stabilizing agent in the synthesis of any metal nanoparticle including AgNPs $[49,85]$. Due to the complex nature of plant extract and the huge number of phytochemicals that are present, it is difficult to identify a specific compound that acts as the reducing and stabilizing agent in the synthesis of nanoparticles. To date, the role of various phytochemicals such as polyphenols (flavonoids, phenolic acid, and terpenoids), organic acid, and proteins have been proposed in the phytosynthesis of metal nanoparticles [86]. Such phytochemicals perform bio-reduction of aqueous metal ions to form a respective zerovalent metal, which further leads to the agglomeration of metal atoms to respective metal nanoparticles [87].

There are some studies suggested that similar mechanisms for phytosynthesis of AgNPs using various plants such as Pelargonium graveolens (geranium) [88] and Azadirachta indica (neem) [89]. The presence of proteins and other secondary metabolites was reported in the extract of different plants used for the synthesis of AgNPs. Furthermore, it was proposed that terpenoid is responsible for the reduction of silver ions. Moreover, it was also demonstrated that proteins present in the leaf extract of geranium play an important role in the stabilization of AgNPs by capping them [88]. Ahmad et al. [90] proposed that free hydrogen released during keto-enol conversion of flavonoids (luteolin and rosmarinic acid) are mainly responsible for the reduction of metal ions to respective nanoparticles.

In another study, it was suggested that the reducing sugars present in the leaf extract of Azadirachta indica might be responsible for the reduction of silver ions to AgNPs [89]. Moreover, various other compounds such as aromatic amine, amide (I) group, secondary alcohols, and phenolic groups have been proposed for phytosynthesis of AgNPs using Coleus aromaticus leaf extract [91]. In addition, the possible role of other phytochemicals, such as various phenolic acids (gallic acid, caffeic acid, ellagic acid, etc.), terpenoids, proteins, and organic acids, etc., in the synthesis of various metal nanoparticles has been critically reviewed [86]. Additionally, it was also observed that the roots of alfalfa have the capability of absorbing silver as AgNPs. An electron microscopic analysis demonstrated the accumulation of silver atoms inside the alfalfa plant tissues, where they underwent nucleation and subsequently formed nanoparticles [92]. Figure 7 shows a schematic representation of the general mechanism involved in the phytosynthesis of AgNPs. 


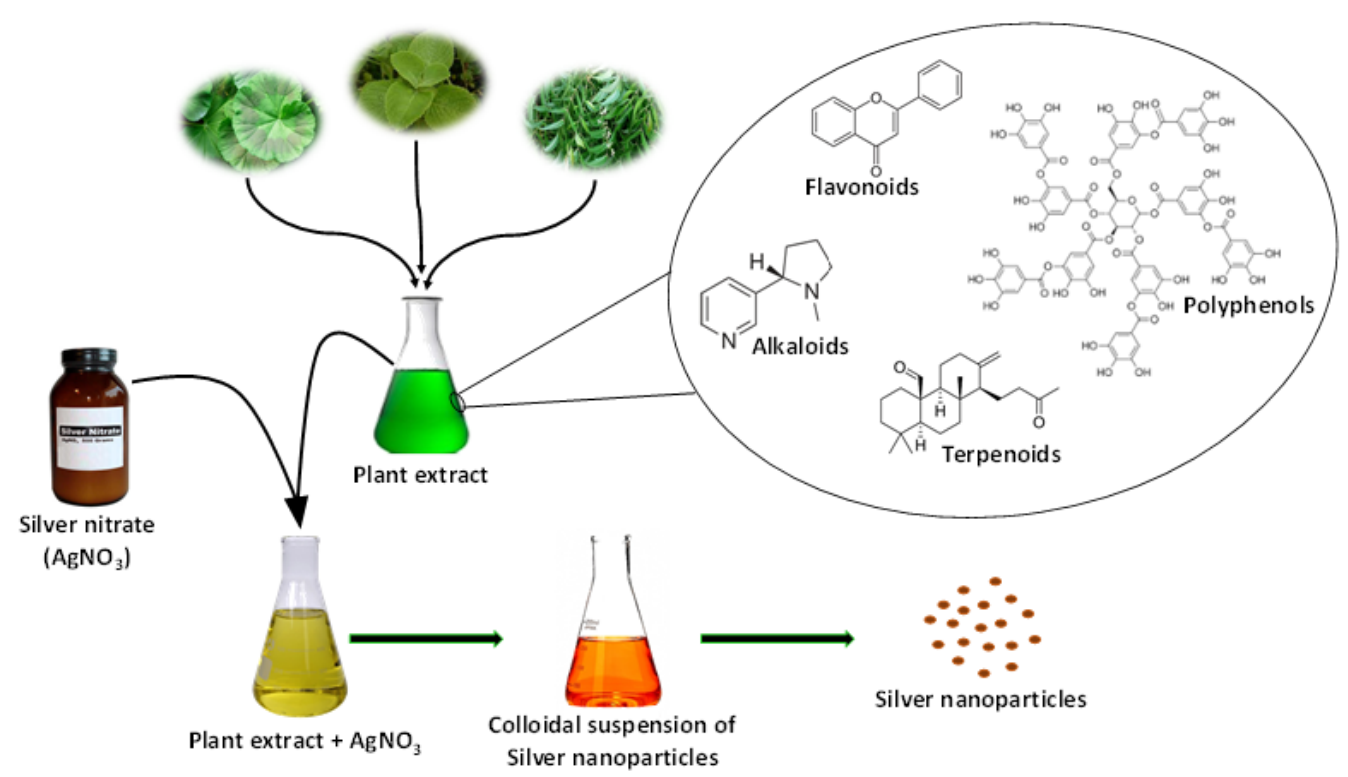

Figure 7. General mechanism involved in the phytosynthesis of AgNPs.

From the above discussion, it can be suggested that different metabolites present in plant extract are responsible for the reduction of metal ions into respective nanoparticles and their capping. In fact, all such capping agents have been found to have the capability of selective binding to different types of facets on nanoparticles, leading to a change in their properties, such as specific surface free energies and their area proportions [93]. Therefore, it is believed that due to capping, nanoparticles can perform several important functions, such as prevention of agglomeration, reduction in toxicity, and enhancement of antimicrobial activity. In addition, there are reports that suggest the enhanced reactivity and catalytic activity of different nanoparticles. Moreover, it was also reported that capping molecules can improve the binding ability of AgNPs on the bacterial cells [94,95]. Similarly, it was reported that the phytochemicals of antimicrobial nature that act as capping agents in phytosynthesis have been found to enhance the antimicrobial efficacy of AgNPs [55].

\section{Purifications of Nanoparticles}

As far as the biogenic synthesis of nanoparticles is concerned, it can be achieved both intracellularly and extracellularly [96]. Some of the biological systems, when exposed to an aqueous solution of metal ions, form nanoparticles intracellularly. Therefore, in such cases, extraction and purification of nanoparticles is essentially required. On the contrary, most biological systems reduce the aqueous metal ions extracellularly, and hence, there is no requirement for the extraction of nanoparticles, but purification is required to remove the impurities present in the form of unreacted components and residues. To date, different techniques have been proposed for the extraction and purification of biogenically synthesized nanoparticles. These techniques mainly include simple filtration, gel filtration, membrane filtration, simple and ultra-centrifugation, electrophoresis, chromatographic methods, chemical or biochemical purification, dialysis, etc. [41,97-100]. Among these techniques, centrifugation techniques are commonly used for the purification of biogenic AgNPs.

In this context, John et al. [101] demonstrated the intracellular synthesis of AgNPs using a Pseudomonas strain. The extraction of the thus synthesized AgNPs was performed by centrifugation of bacterial biomass at $5000 \mathrm{rpm}$ for $30 \mathrm{~min}$. Furthermore, the pellet obtained was suspended in deionized $\mathrm{H}_{2} \mathrm{O}$ followed by ultrasonication at a pulse rate of $6 \mathrm{~V}$ at the intervals of $30 \mathrm{~s}$ for ten cycles. After sonication, the solution was again centrifuged at $5000 \mathrm{rpm}$ for $30 \mathrm{~min}$, and the supernatant was loaded on a Sephadex G50 resin equilibrated in $10 \mathrm{mM}$ Tris buffer ( $\mathrm{pH}$ 7.0). It is required to remove debris and 
proteins. Finally, the AgNPs were extracted from the buffered solution by adding three volumes of isopropanol because isopropyl alcohol is known to dissolve a wide range of non-polar compounds and evaporate quickly when compared with ethanol. In the end, the mixture was kept in an orbital shaker overnight for evaporation of isopropanol to obtain a pure powder of AgNPs. In another study, Netala et al. [102] demonstrated the extracellular biosynthesis of AgNPs using aqueous callus extract of Gymnema sylvestre, and these AgNPs were separated by centrifugation of the solution at 15,000 rpm for $15 \mathrm{~min}$. Furthermore, AgNPs were dispersed in water and purified by repeated centrifugation (five times) to remove the unused callus extract. In another study, Datkhile et al. [103] reported the biogenic synthesis of AgNPs using leaves extract of Nathophodytes foetida. The AgNPs were further purified by centrifugation at 10,000 rpm for $30 \mathrm{~min}$ and washing with double-distilled water, followed by redispersion of the pellet in deionized water. A similar method of centrifugation ( $9000 \mathrm{rpm} ; 20 \mathrm{~min} ; 10^{\circ} \mathrm{C}$ ) was suggested by Mohanta et al. [25] for the purification of AgNPs synthesized from the extract of Protium serratum.

Moreover, Gurunathan et al. [104] performed the extracellular synthesis of AgNPs from Escherichia coli. For the purification, the colloidal solution containing AgNPs was washed 5-6 times with deionized water, followed by centrifugation at 10,000 rpm for $15 \mathrm{~min}$. Then the obtained pellet was resuspended in distilled water to remove the remaining unconverted silver ions. Furthermore, this dispersion containing biogenic AgNPs was transferred to a dialysis tube with a 12,000 molecular weight cutoff. Later, the obtained AgNPs were resuspended in $1 \mathrm{~mL}$ of HEPES buffer $(20 \mathrm{mM}, \mathrm{pH} 7.4)$ supplemented with sucrose to reach a density of $2.5 \mathrm{~g} / \mathrm{mL}$, and a gradient was made according to proposed standard methods. Finally, the AgNPs were purified by density gradient centrifugation using ultracentrifugation at $200,000 \mathrm{rpm}$ at $4{ }^{\circ} \mathrm{C}$ for $16 \mathrm{~h}$. From the above reports, it is clear that centrifugation can be effectively used for the purification of biogenic AgNPs, as it helps to remove untreated ions and other impurities.

\section{Multiple Applications of bio-AgNPs in Different Fields}

Recent advances in the field of nanotechnology have led to the development of different inorganic and organic nanomaterials. Biogenic AgNPs have already demonstrated multiple applications in many sectors, such as electronics, biomedicine, cosmetics, textile industries, crop protection and growth promotion, food packaging, and biofuel industries [105-107]. In recent years, biogenic AgNPs (bio-AgNPs) have attracted the considerable attention of scientists because of their widespread applications in different fields of human life due to their unique properties compared with bulk materials (Figure 8).

Bio-AgNPs have a large active surface area, small size, diverse shapes, biocompatibility, stability, high solubility, and yield without aggregation [50,108-110]. The biocompatibility and stability of biogenic nanoparticles may be related to their natural surface coating, which adds some further functionality to the nanoparticles [111-114]. The widespread applications of bio-AgNPs should also be considered from the ecological and economical point of view, as the biosynthesis process is eco-friendly, easy to perform, and inexpensive $[115,116]$.

\subsection{Biomedical Applications of Biogenic AgNPs}

Nowadays, the applications of various fields of conventional biological sciences, along with innovative and efficient nanotechnological tools for the production of greensynthesized AgNPs, have provided a new alternative strategy and perspective for the prevention and treatment of various diseases [117]. To date, many reports are available that demonstrate the antibacterial, antiviral, antifungal, antiprotozoal, antiparasitic, and anticancer efficacy of bio-AgNPs [9,118-125].

\subsubsection{Antibacterial and Antifungal Activities}

The antimicrobial nature of AgNPs is the most exploited characteristic of nanosilver in the medical field. Due to the increasing antibiotic resistance of bacteria and the inef- 
fectiveness of conventional therapeutics, there is an urgent need to develop new agents to combat existing pathogens in general and new and emerging pathogens in particular. Nanoparticles can be used as alternative and highly effective antimicrobial agents due to their high surface area, chemical reduction properties, and surface reactivity $[9,126-128]$. There are a number of reports on bio-AgNPs synthesized by bacteria, fungi, and plants that have demonstrated antimicrobial potential against pathogenic bacteria and fungi (Table 3).

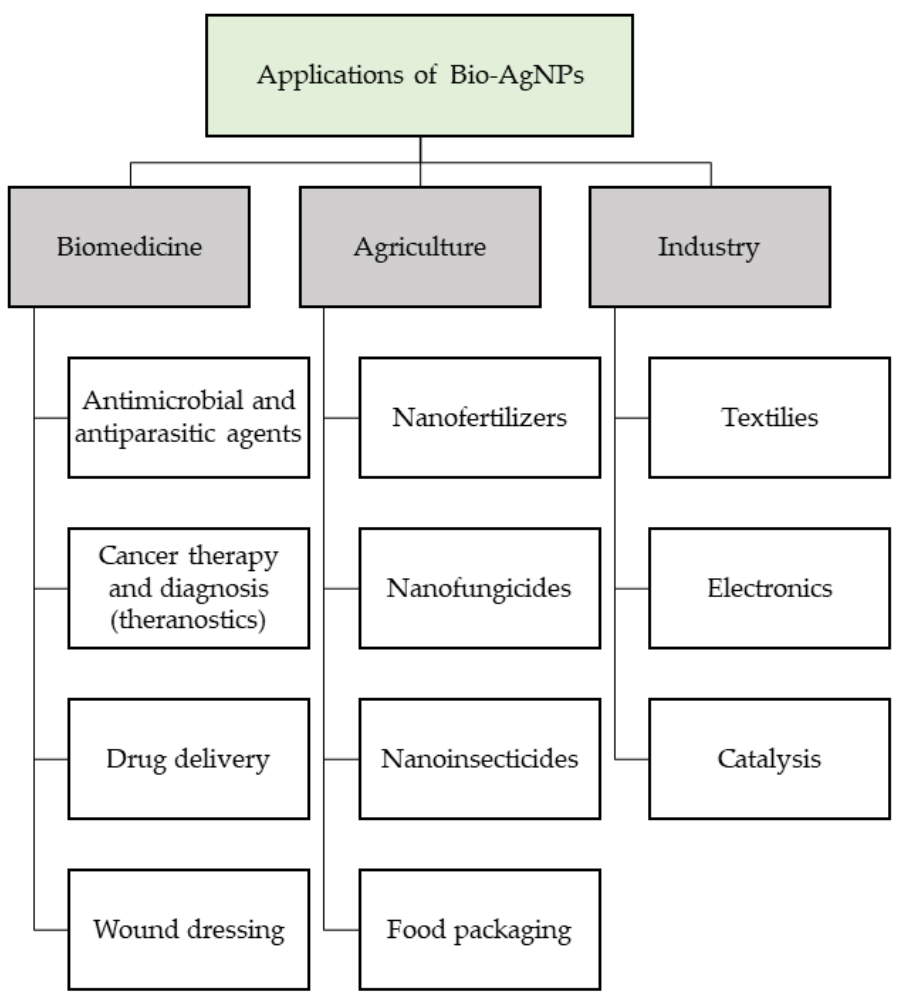

Figure 8. Multiple applications of bio-AgNPs in different fields.

Table 3. Selected examples of biogenic AgNPs and their antimicrobial activity Key: MDR; multidrug-resistant.

\begin{tabular}{|c|c|c|c|}
\hline Organism & Activity & Target & References \\
\hline \multicolumn{4}{|c|}{ Bacteria } \\
\hline $\begin{array}{l}\text { Pilimelia columellifera subsp. } \\
\text { pallida (SF23, C9) }\end{array}$ & antifungal & $\begin{array}{c}\text { Malassezia furfur, Trichophyton rubrum, } \\
\text { Candida albicans, C. tropicalis }\end{array}$ & [129] \\
\hline $\begin{array}{c}\text { Streptomyces sp. OSIP1 and } \\
\text { OSNP14 }\end{array}$ & antibacterial & $\begin{array}{c}\text { Staphylococcus aureus Bacillus subtilis, } \\
\text { Proteus mirabilis Escherichia coli, } \\
\text { Pseudomonas aeruginosa }\end{array}$ & [130] \\
\hline Bacillus cereus & antibacterial & $\begin{array}{c}\text { Escherichia fergusonii, Streptococcus } \\
\text { mutans }\end{array}$ & [131] \\
\hline Pseudomonas rhodesiae & antibacterial & Dickeya dadantii & [132] \\
\hline Alcaligenes sp. & antibacterial and antifungal & $\begin{array}{c}\text { Bacillus sp., Escherichia coli, Klebsiella } \\
\text { pneumonia, Pseudomonas aeruginosa, } \\
\text { Staphylococcus aureus, Candida albicans }\end{array}$ & [133] \\
\hline Bacillus brevis & antibacterial & $\begin{array}{c}\text { MDR Staphylococcus aureus, Salmonella } \\
\text { typhi }\end{array}$ & [134] \\
\hline
\end{tabular}


Table 3. Cont.

\begin{tabular}{|c|c|c|c|}
\hline Organism & Activity & Target & References \\
\hline \multicolumn{4}{|c|}{ Fungi } \\
\hline Nigrospora oryzae & antifungal & Fusarium spp. & [135] \\
\hline Alternaria sp. & antibacterial & $\begin{array}{l}\text { Bacillus subtilis, Staphylococcus aureus, } \\
\text { Escherichia coli, Serratia marcescens }\end{array}$ & [136] \\
\hline Phomopsis helianthi & antibacterial & $\begin{array}{c}\text { Escherichia coli, Pseudomonas aeruginosa } \\
\text { Escherichia coli, Bacillus subtilis, }\end{array}$ & [137] \\
\hline Colletotrichum sp. & antibacterial & $\begin{array}{c}\text { Staphylococcus aureus, Salmonella } \\
\text { typhimurium }\end{array}$ & [138] \\
\hline Aspergillus tubingensis & antifungal & $\begin{array}{c}\text { Candida albicans, Candida glabrata, } \\
\text { Candida parapsilosis }\end{array}$ & [139] \\
\hline Cladosporium cladosporioides & antibacterial and antifungal & $\begin{array}{c}\text { Staphylococcus aureus, Staphylococcus } \\
\text { epidermis, Bacillus subtilis, Escherichia } \\
\text { coli, Candida albicans }\end{array}$ & [140] \\
\hline \multicolumn{4}{|c|}{ Plants } \\
\hline Juglans regia & antibacterial & $\begin{array}{l}\text { Escherichia coli, Pseudomonas aeruginosa, } \\
\text { Staphylococcus aureus }\end{array}$ & [141] \\
\hline Dimocarpus Longan & antibacterial & Escherichia coli, Staphylococcus aureus & [142] \\
\hline Eucalyptus camaldulensis & antifungal & Candida albicans & [143] \\
\hline
\end{tabular}

Overall, bio-AgNPs show a stronger inhibitory effect on Gram-negative than Grampositive bacteria. This difference in efficacy may be due to the variance in thickness of the cell wall present in these bacteria $[9,141,144-146]$. Bio-AgNPs were also found to effectively inhibit biofilm formation in Gram-positive (Stapylococcus aureus) and Gramnegative (Escherichia coli) bacteria [147]. In addition, bio-AgNPs were reported to be active against various human pathogenic fungi such as Trichophyton mentagrophytes, T. rubrum, T. tonsurans, T. violaceum, Malassezia furfur, and Candida species [148-154] and also displayed the antibiofilm activity against $C$. albicans, C. glabrata, and C. tropicalis $[147,153]$.

The antimicrobial efficacies of bio-AgNPs depend upon their physicochemical properties and the biological features of the target pathogens. As far as the mechanism of antimicrobial action of bio-AgNPs is concerned, it can be summarized as follows: (i) electrostatic attraction of bio-AgNPs to cell wall or membrane of microbes, (ii) penetration into the cells, (iii) interaction with biomolecules and intracellular structures, and (iv) free-radical and ROS generation [155]. The changes in cell membrane permeability can cause loss or leakage of intracellular contents, such as ions, proteins, or cellular energy reservoir (ATP), leading to the death of the cell [156]. Bio-AgNPs also affect the function of membranebound enzymes such as those in the respiratory chain $[157,158]$ and cause loss of DNA replication and subsequent inactivation of the ribosomal subunit, leading to inhibition of protein synthesis [159]. There are various reports that demonstrate the mechanism of action of bio-AgNPs. For example, Juniperus excelsa extract was used for the biosynthesis of small AgNPs (around 16-24 nm) with an extremely large surface area, which showed an ability to bind to the membrane, resulting in the lysis of bacterial cells [160]. In another example, nanoparticles synthesized from walnut extract exhibited a significant antimicrobial activity against Gram-negative (Escherichia coli and Pseudomonas aeruginosa) and Grampositive (Bacillus subtilis) bacteria. These bio-AgNPs induced bacterial cell permeability by the disruption of cell membrane integrity, either directly or as a consequence of the antimicrobial activity exhibited by such nanostructures [161,162]. Additionally, bio-AgNPs synthesized from Bacillus cereus (MT193718) indicated significant antibacterial activity against methicillin-resistant Staphylococcus aureus (MRSA) and multidrug-resistant (MRD) K. pneumoniae, with a zone of inhibition of 17 and $18 \mathrm{~mm}$ at a concentration of $1000 \mu \mathrm{g} / \mathrm{mL}$ and minimum inhibitory concentration (MIC) of 15.6 and $62.5 \mu \mathrm{g} / \mathrm{mL}$, respectively. Moreover, these bio-AgNPs were found to be compatible with red blood cells at a concentration of $31.5 \mu \mathrm{g} / \mathrm{mL}$, with no clumping of erythrocytes, which is important to their application 
as a safe therapeutic agent against multidrug-resistant bacteria [114]. Micro-morphological changes were observed in C. albicans cells after treatment with bio-AgNPs synthesized from Citrus limetta peel extract. Bio-AgNPs at $10.7 \mu \mathrm{g} / \mathrm{mL}$ caused the cell blebs and a thick exudate deposition around the cell, indicating the leakage of intracellular substances. In another study, although AgNPs produced by F. oxysporum showed no significant inhibitory effect on biofilm cells of $C$. albicans, their use in combination with fluconazole caused a significant FLC dose-dependent decrease in viability of FLC-resistant C. albicans [163].

\subsubsection{Antiviral Activity}

The bio-AgNPs have been mainly evaluated for their antimicrobial potential against bacteria and fungi. However, their potential against several types of viruses, including human immunodeficiency virus (HIV), hepatitis B virus (HBV), herpes simplex virus (HSV), respiratory syncytial virus (RSV), and monkey pox virus has also been realized [164-166]. The antiviral activity of bio-AgNPs synthesized from marine actinomycete Nocardiopsis alba was evaluated on embryonated chicken eggs infected with Newcastle viral disease (NDV), which causes acute respiratory disease and depression. These bio-AgNPs coated with protein derived from the negatively charged carboxylate groups demonstrated promising antiviral activity [167]. In another study, bio-AgNPs synthesized from Panax ginseng roots showed antiviral activity against influenza A virus (IAV). The authors reported that the antiviral activity was not only a consequence of the intrinsic effects of bio-AgNPs but also due to the anti-influenza activity of secondary metabolite of plant adsorbed onto the surface of the nanoparticles [168]. Based on these studies, it can be suggested that bio-AgNPs can also be used for the treatment of various viral diseases, including acute respiratory syndromes [169]. Although the existing reports showed promising antiviral activity of bio-AgNPs, more studies are still required to prove the use of bio-AgNPs against novel and emerging viruses such as SARS-CoV-2 [112,170,171].

\subsubsection{Antiprotozoal Activity}

Biogenic AgNPs are considered as efficient agents against the protozoan parasites responsible for causing zoonoses in humans-namely, Leishmania amazonensis and Toxoplasma gondii [121,172]. Leishmania causes zoonosis called American Cutaneous Leishmaniasis (ACL) which is known to be difficult to treat with available chemotherapy. Biogenic AgNPs synthesized from Fusarium oxysporum were found to be a potential agent for the treatment of L. amazonensis, in both promastigote and amastigote forms. The bio-AgNPs caused promastigote death, leading to apoptosis-like events due to an increased production of reactive oxygen species (ROS), loss of mitochondrial integrity, phosphatidylserine exposure, and damage of their membrane. Bio-AgNPs reduced the percentage of infected macrophages and the amount of amastigotes per macrophage; consequently, the amount of promastigotes recovered. This biocidal effect of bio-AgNPs was accompanied by a decrease in the ROS level in infected macrophages; thus, bio-AgNPs act on the immunomodulatory ability of infected macrophages, reducing infection without inducing the synthesis of inflammatory mediators. However, the authors suggested further in vivo investigations for a possible bio-AgNP treatment for ACL [121]. In another study, Machado et al. [172] claimed that bio-AgNPs synthesized from F. oxysporum can be used as a therapeutic alternative for toxoplasmosis caused by T. gondii. They revealed that bio-AgNPs effectively reduced adherence, infection, and proliferation of tachyzoites in HeLa cells at concentrations of 3 and $6 \mu \mathrm{M}$ when compared with a conventional drug. Bio-AgNPs at the concentrations tested were not able to induce ROS production in HeLa cells infected with T. gondii [172].

\subsubsection{Anticancer Activity and Theranostics}

Biogenic AgNPs may also be an eco-friendly and biocompatible alternative to conventional anticancer drugs [173]. There are various reports concerning the inhibitory effects of bio-AgNPs on many cancer cell lines (e.g., MCF-7 breast cancer, PC-3 prostate cancer, A549 lung cancer, KB oral cancer, PA1 ovarian cancer) [9,123,142,174-178]. The proposed 
mechanism for anticancer activity of biogenic AgNPs is apoptosis caused through caspasedependent and mitochondria-dependent pathways induced by nanoparticles $[179,180]$. It was reported that B16 melanoma cancer cells treated with bio-AgNPs synthesized from Olax scandens leaf extract had undergone sub-G1 arrest, which might be the reason for apoptosis induction [181]. Anticancer activity of bio-AgNPs was attributed to the generation of ROS. An increased cellular $\mathrm{ROS}\left(\mathrm{O}^{2 \cdot-}, \mathrm{H}_{2} \mathrm{O}_{2}\right)$ influences the signal transduction pathways that play an important role in apoptosis activation [181]. Studies have shown the upregulation of p53 protein in the lysate of B16 melanoma cancer cells treated with bio-AgNPs. It is well established that the bio-AgNPs treatment ultimately triggers p53 upregulation via apoptosis pathway activation, leading to the cell death. Cancer cells treated with bio-AgNPs have upregulated expression of cleaved/active caspase-3, and silver ions released by bio-AgNPs are the main cause of caspase- 3 activation and ultimate oxidative stress [179,181-183]. Moreover, the acidic environment of the tumor was assumed to be the cause of phyto-constituents being released from bio-AgNPs, enhancing the potential anticancer activity of bio- AgNPs [181]. Biogenic AgNPs were found to possess antiangiogenic property with the inhibition of VEGF-induced cell proliferation $[179,184,185]$, which provides another proof that they can be exploited for the development of potent cancer therapeutic agents.

An in vitro analysis also showed that the bio-AgNPs synthesized from actinobacterial strain SF23 demonstrated higher cytotoxicity against MCF-7 breast cancer cells than RAW 264.7 macrophages. In addition, these AgNPs stimulated cancer cells to release a greater amount of ROS than macrophages, which can be correlated with higher cancer cell mortality. These studies indicate that the use of bio-AgNPs may be an effective anticancer therapy itself, while activation of macrophages may additionally involve defense mechanism against tumors [9]. The induced apoptosis, cytotoxicity, and anticancer activity of bio-AgNPs synthesized from Artemisia turcomanica leaf extract against gastric cancer cell lines, in a dose- and time-dependent manner, were reported by Mousavi et al. [180]. Bio-AgNPs synthesized using extract of Sesbania grandiflora L. showed cytotoxic effect against the MCF-7 cancer cell line, causing loss of cell membrane integrity, oxidative stress, and apoptosis [186]. Some reports also proved that bio-AgNPs possess higher anticancer properties than those produced by physical and chemical methods [180]. A lower concentration of phyto-synthesized AgNPs from Artemisia marschalliana was able to inhibit growth of human gastric (AGS) cells when compared with the commercial agents [187]. Moreover, bio-AgNPs are believed to increase the efficiency of a particular anticancer drug by targeting it specifically to particular cancer cells (targeted drug delivery), which will ultimately decrease the dosage of the drug and minimize the side effects [188]. Bio-AgNPs combined with cancer drug doxorubicin showed a significantly elevated anticancer activity on the B16F10 cell line, as compared with the drug attached to chemically synthesized nanoparticles [189].

It is believed that in the future, bio-AgNPs will be promising entities administered for the diagnosis of cancer due to their self-fluorescence ability [179], but to date, the evidence has been insufficient. Researchers reported the self-fluorescence ability of bio-AgNPs synthesized from the methanolic extract of Olax scandens. Cancer cells treated with bio-AgNPs coated with fluorescent molecules from plant extract emitted bright-red fluorescence, indicating the internalization of these nanoparticles by cells. Such observations were not recorded in untreated cells or in cells treated with chemically synthesized AgNPs [179,181].

\subsubsection{Antidiabetic Activity}

Green synthesized AgNPs are also reported as antidiabetic agents; for example, bioAgNPs synthesized from Holoptelea integrifolia were found to possess antidiabetic activity. Although various extracts of $H$. integrifolia have shown antidiabetic activity by the inhibition of the ATP-sensitive potassium channels in the pancreatic beta cells mechanism, the AgNPs synthesized from this plant showed an enhanced effect. This activity of bioAgNPs increased in a dose dependent manner. A $60.08 \pm 3.38 \%$ of $\alpha$-amylase inhibition 
was observed by employing $25 \mu \mathrm{L}$ of tested AgNPs, while in case of plant extract and standard (acarbose) a $45.88 \pm 3.44$ and $72.22 \pm 4.3 \%$ inhibition was observed. At a higher concentration of $100 \mu \mathrm{L}$, the percentage of enzyme inhibition in the presence of AgNPs, extract, and acarbose was $86.66 \pm 5.03,71.28 \pm 4.33$, and $95.01 \pm 5.41 \%$, respectively [189]. The studies concerning the antidiabetic properties of bio-AgNPs are scanty, and therefore, more research concerning efficacy and toxicity are needed to draw conclusions.

\subsection{Antioxidant Activity}

It is well known that antioxidants protect cells against free radicals. An antioxidant stops oxidation by neutralization of produced free radicals, as a result of which it undergoes oxidation [190]. Antioxidant activity of bio-AgNPs refers to the formation of non-reactive stable radicals through an inhibition of the oxidation of molecules by preventing the initiation step of the oxidative chain reaction. The antioxidant potential of bio-AgNPs depends on the properties of various molecules deposited on their surface. The capping of reduced silver by secondary metabolites may augment the involvement of synthesized AgNPs towards the antioxidant property [189].

Bio-AgNPs synthesized from the aqueous extract of Holoptelea integrifolia leaves exhibited significant antioxidant activity (51.49 $\pm 3.33 \%$ for 2,2-diphenyl-1- picrylhydrazylhydrate (DPPH), $41.18 \pm 2.27$ for metal chelating (MC), and $74.59 \pm 3.08 \%$ for nitric oxide (NO) assays) at the highest tested concentration of NPs. In DPPH, MC, and NO assays, a concentration-dependent effect was noticed for these AgNPs. The lower values in the case of DPPH and MC assays when compared with the NO assay was attributed to the secondary metabolites that were present in low concentrations of $H$. integrifolia extract. It was interpreted that in the case of the MC assay, secondary metabolites had a capping mechanism with silver metal, so they were not free; hence, low MC properties were acceptable. Moreover, it was claimed that different biomolecules may affect different antioxidant properties when estimated using different antioxidant assays but that they can help in reducing oxidative stress in cells. The authors also claimed that biogenic nanosilver could serve as a free radical scavenger, possibly acting as a primary antioxidant. Bio-AgNPs may be a good alternative to synthetic antioxidants having adverse health effects, such as butylated hydroxyl toluene, butylated hydroxyl anisole, and propyl gallate [189]. Similarly, Ibrahim et al. [190] reported effective antioxidant properties of bio-AgNPs synthesized by Bacillus cereus using DPPH and 2,2'-azino-bis-3-ethylbenzothiazoline-6-sulfonic acid (ABTS) assays.

\subsection{Application of Biogenic AgNPs in Agriculture}

Crop pathogens reduce the yield and quality of agricultural production [191]. Various strategies are used in the management of plant diseases, but some of them impose a serious negative impact on the environment [192]. By providing new agrochemicals and tools for delivering active compounds, nanotechnology offers the possibility of reducing and optimizing the use of conventional products, such as toxic pesticides [193].

\subsubsection{Plant Protection}

The antifungal activity of biogenic AgNPs against important phytopathogens (e.g., Fusarium oxysporum, F. tricinctum, Botrytis cinerea, Penicillium expansum, Aspergillus niger, Alternaria sp., and Rhizopus sp.) has been reported by many authors [119,194-196], but mainly in vitro. The bio-AgNPs synthesized by Serratia sp. BHU-S4 were examined under in vitro conditions for antifungal activity against Bipolaris sorokiniana, the spot blotch pathogen of wheat. Bio-AgNPs accounted for total inhibition of conidial germination. The biocontrol potential of AgNPs against B. sorokiniana was also confirmed by in vivo assay. B. sorokiniana after nanoparticle treatment did not develop spot blotch on wheat leaves [197]. In another study, bio-AgNPs fabricated using Nigrospora oryzae, the corn grain contaminant, exhibited dose-dependent antifungal activity against Fusarium spp., an important plant pathogenic fungus [135]. Bio-AgNPs synthesized from leaves extract 
of Acalypha indica at a concentration of $15 \mathrm{mg} / 10 \mu \mathrm{l}$ showed strong antifungal activity against all tested fungi (Alternaria alternata, Botrytis cinerea, Curvularia lunata, Rhizoctonia solani, Sclerotinia sclerotiorum, and Macrophomina phaseolina), which was evident from the inhibition zones of growth in the range of 18-23 mm [198]. In addition, the nematicidal activity of bio-AgNP was confirmed against plant parasitic nematode Meloidogyne incognita. Encouragingly, bio-AgNPs significantly reduced the nematode activity, mortality, egg hatching, and movement of larvae. In another experiment, instead of chemical nematicide products, bio-AgNPs synthesized using Acalypha wilkesiana aqueous extract could be recommended to manage the plant-parasitic nematode, as a simple, stable, and costeffective way of keeping the environment safe [199]. It is expected that the application of bio-AgNPs at low concentrations will be eco-friendly and will decrease farm management costs. Based on the above discussion and the potential role of bio-AgNPs against plant pathogens, it is evident that these may be used as an alternative solution for controlling microbial pathogens affecting plant growth instead of using synthetic chemicals. However, it is necessary to determine the exact mechanism of bio-AgNPs action in the fungal cell and their impact on the environment and human beings [200].

\subsubsection{Plant Growth Promotion}

Nanoparticles can increase the vigor of the crops to withstand the impact of pests and diseases [193]. There are many reports indicating that, in low concentrations, bio-AgNPs have a positive effect on seed germination and the promotion of plant growth [201]. For example, AgNPs synthesized by a green method using Berberis lycium Royle extract had the capacity to improve crop growth and yield [202]. In another study, bio-AgNPs synthesized by using the aqueous extract of Euphorbia helioscopia leaves, when applied on seeds and as foliar sprays, had a positive impact on the morphology of seed oil, enzymes, and fatty acid content of sunflower [203]. Bio-AgNPs synthesized from a marine endophytic fungus, Fusarium equiseti, displayed positive effects on wet weight, shoot length, root length, chlorophyll, and carotenoid content, even at a lower concentration of $5 \mathrm{ppm}$. These results suggest that bio-AgNPs could be used as a nanofertilizer after performing further toxicity studies under field conditions [204]. Zhang et al. [205] compared chemically (chem-AgNPs) and biologically (bio-AgNPs) synthesized AgNPs. It was found that chem-AgNPs had strong antibacterial activity against $E$. coli, while bio-AgNPs exhibited long-term antibacterial effects. In addition, chem-AgNPs showed toxic effects on cucumber plants by inducing over-generation of ROS, thus resulting in the upregulation of malondialdehyde (MDA) and $\mathrm{Zn}$ content and the downregulation of antioxidant capacity, carotenoid, globulin, and Mo content, while biogenic AgNPs significantly promoted photosynthesis in cucumber. Moreover, bio-AgNPs enhanced the protein content and stimulated the upregulation of $\mathrm{Mn}$ and downregulation of Al. Nevertheless, after treatment with bio-AgNPs, the downregulation of Mo and the upregulation of $\mathrm{Al}$ indicated minimal toxicity to cucumber plants. Overall, bio-AgNPs when compared with chem-AgNPs exhibited limited toxic effects to cucumber plants. Bio-AgNPs have been proven to be biocompatible, well-dispersed, and because of their high efficiency and low toxicity, could be used as nanopesticides in agriculture [205].

\subsection{Food Packaging}

Bacterial and fungal contaminants can spoil food by degrading its quality and causing an unpleasant taste. In addition, microbial contamination of food poses a threat to human health [206]. Bio-AgNPs incorporated with biopolymers may find applications as protective agents in food storage and preservation [207]. Biodegradable nanocomposite films can be developed by incorporating AgNPs into the gelatin biopolymer matrix for food packaging applications. Bio-AgNPs were synthesized by using industrial food waste cassava tuber peels which showed significant antimicrobial activity, depicting their capability of being used in a wide range of applications in food and pharmaceutical industries. Moreover, the integration of AgNPs improved the mechanical and barrier properties of gelatin film. The nanocomposite films increased the shelf life of sapodilla fruits, which indicated the potential 
of the films for the food packaging industry, as a way of extending the shelf life of packaged food by up to 12-15 days [208]. Antioxidant and antimicrobial AgNPs synthesized by using Mussaenda frondosa leaves extract were loaded into gelatin/chitosan composite films that enhanced the shelf life of vegetables and fruits. From an ecological point of view, the use of biodegradable AgNPs films may reduce synthetic plastics consumption and environmental harm and may promote healthy foods [209]. In another study, Myxobacteria virescens synthesized AgNPs were impregnated into fruit wrapping paper, which increased the shelf life of apples up to 15 days as compared with the non-impregnated wrapper [210].

\subsection{Smart Nanotextiles}

Nanotechnology is already having a huge impact on the textile industry. Nanocoating of the surface of textiles or footwear is one approach for the production of highly active surfaces with UV blocking, antimicrobial, and self-cleaning properties [211,212]. Biologically synthesized AgNPs from Azadirachta indica leaf extract were used in sock fabrics (nylon and cotton), being antimicrobial in nature. These nanosilver-coated socks were found to have a highly active surface with antimicrobial and self-cleaning properties. The anti-odor, non-toxic, and durable properties of the textiles were also confirmed. Therefore, bio-AgNPs can be effective in reducing foot-borne infections and can be used for various applications, including applications in healthcare and medicine [211]. The inclusion of bio-AgNPs into cotton fibers improved their thermal stability and elongation properties. Moreover, fibers embedded with nanoparticles exhibited remarkable antimicrobial activity against $E$. coli. Therefore, these fibers have great potential for utilization, e.g., in burn/wound dressings, as well as in the fabrication of antibacterial finishing of textiles [213]. It was reported, that AgNPs adhered to or inserted into textile fibers exhibited an effective antibacterial activity against Bacillus subtilis by release of $\mathrm{Ag}^{+}$ions [214]. Multifunctional cotton fabric was also prepared through a simple method based on the coating of the fabric with AgNPs and low surface energy silane. The prepared fabric simultaneously gained functionalities, such as water repellency, antibacterial activity, and UV-blocking [215]. The UV-protection abilities of wool were highly improved with the application of bio-AgNPs. AgNPs were in situ synthesized by using natural compounds and biomolecules of plant extracts (naphthoquinones, phenolics/flavonoids, polyphenols) as reducing or stabilizing agents and were simultaneously deposited on wool fabric for coloration, UV protection, and antioxidant properties. The antioxidant activity of material mainly depends on reducing/stabilizing compounds of nanoparticles from plant extract [216]. The AgNPs synthesis was carried out using aqueous extract of lemon leaves (Citrus limon), which acts as a reducing agent and encapsulating cage for the AgNPs. By incorporating nanoscale silver into textiles, the manufacturers can make materials that use a small amount of silver for elimination of the microbes present on the surface of the clothing material. Such AgNPs that have relatively large surface area available are ideally suited for the effective control of bacteria and molds and can help to prevent spoilage from microbial growth in damp areas [217]. Multifunctional viscose fibers were successfully prepared by simultaneous dyeing and incorporation of bio-AgNPs that were fabricated through a green approach using compounds extracted from peanut red skin. The obtained fabric exhibited UV protection, antimicrobial activity, and coloration, as well as antioxidant activity [218]. Cotton fabric with multi-protective properties was achieved by the environmentally friendly in situ synthesis of AgNPs. The plant material from food waste (e.g., green tea, avocado seed, and pomegranate peel) and invasive plant material (e.g., Japanese knotweed rhizome, goldenrod flowers, and staghorn sumac fruit) were used as reducing agents for the formation of AgNPs directly on cotton fabrics, which provided excellent protection against UV radiation as well as against Escherichia coli and Staphylococcus aureus bacteria [219].

\subsection{Catalytic Activity}

Biogenic AgNPs act as catalysts for the degradation of organic dyes (methylene blue, methyl orange, congo red tartrazine, carmoisine, and brilliant blue FCF) and other 
toxic compounds such as 4-nitrophenol to non-toxic compounds [220-222], which reduces environmental pollution [221]. Bio-AgNPs synthesized from aqueous Prosopis juliflora leaves extract were evaluated for catalytic activity against azo dyes such a methylene blue $(\mathrm{MB})$ and congo red (CR) that resulted in its effective degradation of toxic compounds in a short span of time. The reduction of dyes became faster in the presence of bio-AgNPs than $\mathrm{NaBH}_{4}$. In addition, MB was reduced faster in the presence of bio-AgNPs when compared with CR. Moreover, the reduction of 4-nitrophenol to non-toxic 4-aminophenol was investigated with aqueous $\mathrm{NaBH}_{4}$ along with AgNPs that acted as a catalyst for the reaction. Although the reduction of 4-NP into 4-AP with $\mathrm{NaBH}_{4}$ can be possible, it is limited by kinetic barriers due to the difference in the thermodynamic potential of an electron donor $\left(\mathrm{NaBH}_{4}\right)$ and acceptor (4-NP) that decreases the feasibility of the reaction. In this case, the use of AgNPs as nanocatalysts facilitated the electron relay from donor to acceptor $[190,220]$. Similarly, bio-AgNPs synthesized from the fruit extract of Viburnum opulus L. were found to have catalytic ability in the degradation of tartrazine, carmoisine, and brilliant blue FCF dyes by $\mathrm{NaBH}_{4}$ as reducing agent. The results demonstrated remarkable activity against all the investigated dyes, being an outstanding catalyst for the degradation of brilliant blue FCF. The authors concluded that bio-AgNPs can be used as powerful tools for reducing environmental pollution from organic dyes [221]. The reduction of 4-NP to 4-AP and the degradation of methyl orange (MO) and $\mathrm{MB}$ in the presence of sodium borohydride and catalyzed by bio-AgNPs synthesized using aqueous extract of fruit peel (Citrus macroptera) and bacteria (Bacillus cereus) were also reported recently [190,222]. Considering the above facts, it can be inferred that bio-AgNPs can be used as catalysts for the degradation of dyes.

\subsection{AgNPs in Sensor Development}

In addition to various biological and catalytic properties, the unique opto-electronic properties possessed by silver nanoparticles have opened the door for their use in sensing applications. Although this field is not fully explored, there are a few reports available on the application of biogenic AgNPs in the development of nanosensors. Nanosensors are used for different purposes, including the detection of heavy metal ions and the degradation of complex compounds, dyes, pollutants, and other contaminants that have extremely low detection limits [223]. Actually, heavy metals and other contaminants are generated in the environment as a result of both human and industrial activities, and these are found to be toxic to almost all living forms in higher concentrations. Therefore, detection and degradation of such compounds are necessary. Certain conventional methods are already available for this purpose, but considering their limitations, newer, highly effective approaches need to be developed. However, in view of the noteworthy applications of nanotechnology in general and biogenic nanoparticles in particular, it is believed that biogenic AgNPs can be effectively used in the development of sensors that can be promisingly used in the detection of various contaminants and also in helping with the degradation of toxic compounds in the environment. Some available reports on biogenic AgNPs-based sensors are discussed briefly here.

As mentioned above, the presence of heavy metal ions in the environment is a global health concern. Therefore, their removal is required to minimize environmental pollution. In this context, Hoyos et al. [224] developed a nanosensor using AgNPs synthesized from an aqueous extract of Camellia sinensis (green tea) having a mean diameter of $7 \mathrm{~nm}$. Furthermore, these green synthesized AgNPs were found to exhibit good sensing properties towards $\mathrm{Cu}^{2+}$ and $\mathrm{Pb}^{2+}$ ions in aqueous solutions. This metal ions-sensing ability of the biogenic AgNPs was recorded with help of UV-Vis spectrophotometry (SPR analyses) and fluorescence spectroscopy. Recently, Al-Thabaiti and Khan [225] synthesized biogenic AgNPs by anthocyanin obtained from red rose petals. Furthermore, the thus synthesized AgNPs were used as a sensor for the detection of bromothymol blue and also as a catalyst for the oxidative degradation of bromothymol blue in the presence of sodium borohydride, hydrogen peroxide, and sunlight. In another study, Hussain et al. [226] developed nano-based sensors using biogenic AgNPs synthesized from an aqueous extract 
of clove (Syzygium aromaticum). These AgNPs were used as a colorimetric sensor for the detection of trace amounts of vinclozolin (fungicide) by UV-Vis spectroscopy for the first time. The authors claimed that these biogenic AgNP-based sensors were found to be very sensitive, simple, green, economically viable, and highly selective in colorimetric detection of vinclozolin.

In another study, Tagad et al. [227] used biogenically synthesized AgNPs from locust bean gum (LBG) polysaccharides in the development of optical fiber-based hydrogen peroxide $\left(\mathrm{H}_{2} \mathrm{O}_{2}\right)$ sensors. $\mathrm{H}_{2} \mathrm{O}_{2}$ is commonly used in water treatment plants and other various industries for disinfection and cleaning microcircuits. The access concentration of $\mathrm{H}_{2} \mathrm{O}_{2}$ induces many kinds of cellular damage; therefore, the determination of $\mathrm{H}_{2} \mathrm{O}_{2}$ level is of great importance. In addition, the concentration of $\mathrm{H}_{2} \mathrm{O}_{2}$ needs to be monitored in food and pharmaceutical industries and clinical laboratories. Therefore, the above discussed $\mathrm{H}_{2} \mathrm{O}_{2}$ sensor can be effectively used for this purpose. Similarly, Wani et al. [223] reviewed the role of biogenically synthesized AgNPs in the development of colorimetric and electrochemical sensors, which can be promisingly used for the detection of various pollutants, such as heavy metal ions, $\mathrm{H}_{2} \mathrm{O}_{2}, \mathrm{NH}_{3}$, nitrite ions, sulfide ions, kanamycin, nitrobenzene, and biomolecules such as nucleic acids, aminoamides, etc. Furthermore, the authors concluded that biogenic AgNPs can be used as a promising material for the optical and electrochemical sensing of various types of pollutants in water and soil. Moreover, these nano-based sensors could be very effective for the detection of various biomolecules.

\section{Biodistribution of AgNPs}

The biogenic AgNPs not only helps in the design of safer nanomaterials but also assists in providing a better understanding of health and safety concerns. The biomaterial-based methods do not require the use of hazardous chemicals; therefore, useful products can be generated quickly at a reasonable scale and in an eco-friendly manner [228]. There is a lack of appropriate and standard characterization methodologies that might be used for research evaluating the toxicity of AgNPs to compare the results of different investigations employing similar NPs. Biogenic nanoparticles are harmless, environmentally benign, and contribute to a greener approach. As discussed before, bio-AgNPs can also be used in a variety of research and technology sectors. However, there are some concerns that must be addressed, such as choice of synthesis method, biodistribution, and toxicity issues [228,229]. Biosynthesis utilizing plant extracts for antimicrobial applications, biocidal characteristics, and cytotoxicity depends on physiochemical parameters such as size, concentration, and coating - all of which have been discussed in recent studies [229,230]. AgNPs can cause inflammation and oxidative stress at the site of exposure. Furthermore, they have the ability to penetrate a variety of biological barriers and reach systemic circulation. AgNPs that have been administered intravenously are immediately accessible in circulation. AgNPs are subsequently transported to numerous organs, where they produce organ-specific pathogenic consequences. It is unclear whether the effects found in distant organs are due to the direct impact of translocated AgNPs or particle-induced inflammatory and oxidative stress responses at the exposure site. Ferdous et al. [231] demonstrated AgNPs translocation, accumulation, and toxicity to numerous organs following various modes of exposure, such as inhalation, instillation, and the oral, cutaneous, and intravenous route. Particle size, coating, route, and length of exposure, dosages, and endpoint measurement time all impact the effects on local and distant organs.

Subchronic inhalation or injection of AgNPs demonstrated the uptake of silver ions and nanoparticles in the blood and subsequent distribution to all major organs and tissues, including the liver, kidneys, testes, ovaries, olfactory bulb, and brain. However, the level of accumulation of AgNPs in different organs was found to be different [232] (Figure 9). Human bodies are vulnerable to AgNPs when such AgNPs are consumed, inhaled, or absorbed through the skin because of the large surface area-to-volume ratio, and their penetrating potential is greatly increased, allowing them to penetrate the circulatory system and even to translocate freely within the human body system [233,234]. Yang et al. [235] 
revealed that the size, surface functionalization, and concentration of AgNPs all have a role in in vivo dispersion. Furthermore, AgNPs' inherent chemical composition resulted in erratic biodistribution and hazardous profiles, which received some attention. The biodistribution, toxicity kinetics, and genotoxicity variations in murine animals were studied using AgNPs.

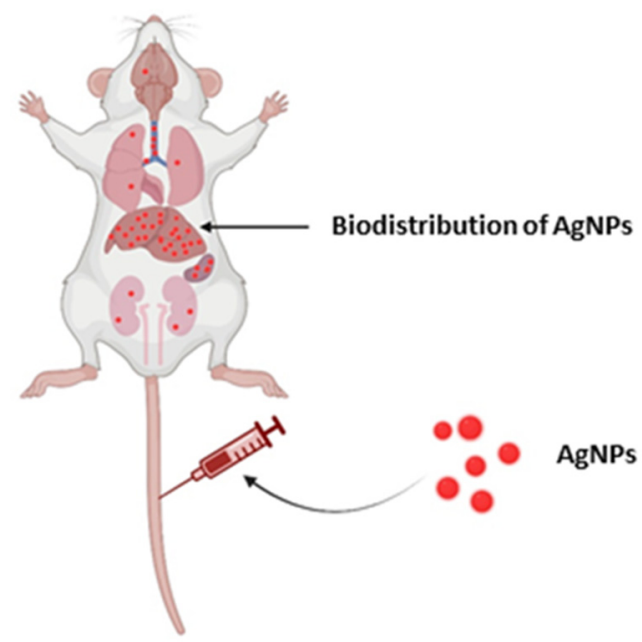

Figure 9. Biodistribution of AgNPs in rat organs.

AgNPs were predominantly deposited in the mononuclear phagocyte system (MPS), such as the liver and spleen. The AgNPs were accumulated in organs, such as the heart, lung, kidney, and other organs. AgNPs were also found in greater concentrations in the circulation and feces. Over the course of two months, measurements of mouse body and organ mass, hematological and biochemistry evaluations, and histological investigations revealed a little harmful effect of AgNPs. AgNPs caused higher alterations in gene expression related to oxidative stress, apoptosis, and ion transport, according to RT qPCR results. The chemical properties of NPs were demonstrated by their findings. Male Wistar rats were given AgNPs (20 and $200 \mathrm{~nm}$ ) intravenously at a dosage of $5 \mathrm{mg} / \mathrm{kg}$ of body weight. Following injection, biological samples were collected after $24 \mathrm{~h}, 7$ days, and 28 days. The concentration of silver in tissue was determined using inductively coupled plasma-mass spectrometry (ICP-MS) and transmission electron microscopy after AgNPs were translocated from the blood to the main organs (TEM). The liver contained the highest amount of silver after $24 \mathrm{~h}$. After 7 days, a considerable quantity of silver was found in the lungs and spleen. The concentration of silver in the kidneys and brain increased during the experiment, reaching a peak after 28 days. Furthermore, the highest concentration of AgNPs was identified in the urine 1 day after the injection, stayed high for 14 days, and then dropped. The final results showed that the fecal level of silver in rats peaked two days after AgNPs treatment and subsequently gradually declined [236].

Zande et al. [237] investigated AgNPs biodistribution in rats. They presented the findings of a 28-day oral exposure trial in rats that were given either $20 \mathrm{~nm}$ noncoated AgNPs or $15 \mathrm{~nm}$ PVP-coated AgNPs $\left(90 \mathrm{mg} / \mathrm{kg}\right.$ body weight or $\mathrm{AgNO}_{3}(\mathrm{Ag})=9 \mathrm{mg} / \mathrm{kg}$ body weight) or a carrier solution. After dissecting on day 29 and a 1- or 8-week wash-out period, AgNPs were found in all of the organs tested, with the greatest amounts in the liver and spleen for all treatments. The quantity of $\mathrm{Ag}^{+}$in the silver nanoparticle solution was significantly associated with silver concentrations in the organs, showing that predominantly $\mathrm{Ag}^{+}$, and to a lesser degree AgNPs, went through the intestines in silver nanoparticle-exposed rats. After 8 weeks, silver was removed from most organs in all groups, but not from the brain or testis. Using single particle inductively coupled plasma mass spectrometry, AgNPs were detected in silver nanoparticle-exposed rats, but remarkably also in $\mathrm{AgNO}_{3}$ exposed rats, hereby demonstrating the formation of nanoparticles from $\mathrm{Ag}^{+}$in vivo that are probably composed of silver salts. The silver exposure did not 
cause hepatotoxicity or immunotoxicity, according to biochemical indicators and antibody levels in the blood, lymphocyte proliferation and cytokine production, and NK-cell activity. Finally, it appears that oral exposure to AgNPs is quite comparable with oral exposure to silver salts. However, the long-term effects of AgNPs in vivo and long-term preservation of AgNPs are unknown [238].

\section{Toxicity of Biogenic AgNPs}

Nowadays, the nanomaterials, especially nanoparticles (NPs), are being widely used; therefore, their fabrication and application have resulted in public awareness of their toxicity and impact on the environment $[15,238]$. In addition to the wide range of applications of AgNPs, it is very crucial to take account of in vivo-associated toxicity and immunoreactivity. Worldwide reports on the toxic effects of NPs that were aimed at identifying the targets and mechanisms of their harmful effects were carried out mainly using different cell culture models, including cancer cell lines $[9,239]$. However, the effect of bio-AgNPs on the latter was discussed earlier. In contrast, few studies on the patterns of NPs transport, accumulation, degradation, and elimination using animal models have been performed [55]. For this reason, in recent years, the number of nanotoxicology studies that have investigated the biological pathways affected by nanoparticles and induced toxic effects has increased substantially [240]. There is no doubt that deeper knowledge of the mechanisms of bio-AgNPs' effect on living organisms will discover new areas of their application in the near future.

Overall, it is claimed that chemically synthesized AgNPs have high in vivo cyto- and genotoxicity as compared with biogenic AgNPs, proposing the latter to be less toxic and biocompatible for potential applications [179,241].

Cytotoxicity effects of biogenic AgNPs against eukaryotic cells have been reported by many authors $[9,23,123]$. Researchers around the world provided new approaches for a more comprehensive understanding of the mechanism of NP-induced toxicity [55]. It is claimed that cytotoxicity of AgNPs is largely mediated by the action of $\mathrm{Ag}^{+}$ions released from nanoparticles [242] that interact with cells and intracellular macromolecules such as proteins and DNA [243]. Moreover, other authors suggested that one of the potential mechanism of bio-AgNPs cytotoxicity is the generation of ROS and superoxide synthesis following reduction of oxygen by electron from electron transport chain on the mitochondrial surface $[9,55,244]$. The generated ROS thus lead to oxidative damage of cellular contents including DNA [242], proteins, and lipids [230,242], and consequently to cell death [242] or to apoptosis [182,183]. The study by Wypij et al. [9] showed that AgNPsstimulated MCF-7 cells released a greater amount of ROS than RAW 264.7 macrophages, which correlated with higher cancer cell mortality. The authors suggested that AgNPsinduced cell death can be partially mediated by ROS production. However, their previous studies are in contradiction to the above-mentioned report. In this case the higher sensitivity of the macrophages to the AgNPs was explained as a ROS-dependent phenomenon, which may be related to the scavenger receptor pathway and the scavenger function of macrophages that increase their sensitivity to the effects of nanoparticles [123]. Moreover, AgNPs themselves may have a devastating effect on the protective antioxidant enzymes, resulting in cellular damage by oxidizing vital biomolecules, subsequently leading to cell death [244].

In addition, ions released from AgNPs may increase the cytotoxic effect of AgNPs by inducing cascades that lead to intracellular toxicity, defined as the "Trojan horse effect" [55]. Akter et al. [230] underlines that the mechanism generation of free radicals occurs after interaction of NPs with cellular components, especially with mitochondria. According to El-Naggar and coauthors [244], apoptosis could be activated through mitochondrial dysfunction, which potentially inhibits the proliferation of cells. Wypij and coauthors [9] estimated the reactive oxygen species (ROS) level in the presence of biosynthesized AgNPs on MCF-7 human breast cancer cell line and murine macrophage cell line RAW 264.7. However, some eukaryotic cells are more prone to nanomaterials, especially AgNPs, than 
to others due to the presence of both the released Ag ions and AgNPs $[15,240]$. Hamida and coauthors [245] showed that AgNPs induced the greatest toxic effects against HepG2 cells when compared with MCF-7 and Caco-2. The authors emphasized that such effect could have been due to charge and the type of biomolecules surrounding AgNPs.

The toxicity of nanoparticles to the cells also depends on their size, shape, and coating/capping agent, and their concentration and surface composition. Many of these conclusions come from the study of the effects of AgNPs on cancer cells [15,122,243]. According to Recordati and coauthors [246], smaller AgNPs due to their larger surface areato-volume ratio have a faster rate of releasing of the silver ion $\left(\mathrm{Ag}^{+}\right)$, hence an increased bioavailability, enhanced distribution, and toxicity of Ag compared with larger NPs. The significant impact of AgNPs size on their biological activity has been reported by many authors [243,247,248]. Ashajyothi and Chandrakanth [240] studied animal toxicity using 11-75 nm biogenic AgNPs (bio-AgNPs) in the male Wistar rat. It was also reported that the cytotoxicity of bio-AgNPs against normal and cancer cell lines is dose-dependent. In many cases, nanoparticles at low concentrations do not cause significant toxicity $[9,123,247,249]$. The shape of the AgNPs might influence the cellular uptake mechanism, which in turn modulates the cytotoxicity [230]. An important aspect in biogenic nanoparticle toxicity is their coating. The biogenic nanoparticles can be synthesized by using organisms or by products of their metabolism. Therefore, these nanoparticles are capped with biomolecules of natural origin that can improve stability and determine their biological activity and cytotoxicity [250].

\section{Conclusions}

Nanotechnology is playing a pivotal role in the day-to-day life of human beings due to its wide-range of applications. Nanoparticles are the tools of nanotechnology that can be synthesized by physical, chemical, and biological methods. The latter is green, sustainable, rapid, and economically viable process of synthesis. These biogenic nanoparticles have demonstrated multiple applications, such as in the biomedical field, agriculture, as catalysts, in textiles, as biosensors, and so on. As far as the biomedical sector is concerned, nanomaterials in general and AgNPs in particular are considered as magic bullets that can revolutionize this sector by the development of newer nanobased antimicrobials or by their application in drug delivery. Biogenic AgNPs have been reported to have better biological efficacies over physically and chemically synthesized nanoparticles due to their biocompatibility and enhanced biological properties. Moreover, also in agriculture, biogenically synthesized nanoparticles have been found to enhance the growth of crop plants and may protect them from the attack of pathogens and pests. The AgNPs can also be used for gene transfer in plants. Various efforts have been made to elucidate the exact mechanisms involved in the biogenic synthesis of AgNPs, but unfortunately, to date no such mechanism is known.

Author Contributions: Conceptualization, M.R., and P.G.; writing—original draft preparation, A.P.I., A.Y., J.T.-W., M.W., M.R., P.G., and S.B.; writing-review and editing, M.R., P.G., and G.K.; visualization, A.Y., A.P.I., J.T-W., S.B., and G.K.; supervision, M.R., and P.G.; funding acquisition, M.W. All authors have read and agreed to the published version of the manuscript.

Funding: ACP was funded by the National Science Centre (NSC), grant Preludium (no. 2016/23/N / NZ9/00247).

Institutional Review Board Statement: Not applicable.

Informed Consent Statement: Not applicable.

Acknowledgments: M.R. and P.G. would like to thank the Polish National Agency for Academic Exchange (NAWA) for financial support under the grant PPN/ULM/2019/1/00117/DEC/1 201910-02. A.P.I. is highly thankful to the Science and Engineering Research Board (SERB), Department of Science and Technology, Government of India, New Delhi, for providing financial support in the form of a Ramanujan Fellowship (RJF/2019/000044). 
Conflicts of Interest: The authors declare no conflict of interest.

\section{References}

1. Bayda, S.; Adeel, M.; Tuccinardi, T.; Cordani, M.; Rizzolio, F. The History of Nanoscience and Nanotechnology: From ChemicalPhysical Applications to Nanomedicine. Molecules 2020, 25, 112. [CrossRef] [PubMed]

2. Wu, Q.; Miao, W.; Zhang, Y.; Gao, H.; Hui, D. Mechanical properties of nanomaterials: A review. Nanotechnol. Rev. 2020, 9, 259-273. [CrossRef]

3. Bawskar, M.; Deshmukh, S.; Bansod, S.; Gade, A.; Rai, M. Comparative analysis of biosynthesised and chemosynthesised silver nanoparticles with special reference to their antibacterial activity against pathogens. IET Nanobiotechnol. 2015, 9, 107-113. [CrossRef] [PubMed]

4. $\quad$ Paosen, S.; Jindapol, S.; Soontarach, R.; Voravuthikunchai, S.P. Eucalyptus citriodora leaf extract-mediated biosynthesis of silver nanoparticles: Broad antimicrobial spectrum and mechanisms of action against hospital-acquired pathogens. APMIS 2019, 127, 764-778. [CrossRef]

5. Loiseau, A.; Asila, V.; Boitel-Aullen, G.; Lam, M.; Salmain, M.; Boujday, S. Silver-based plasmonic nanoparticles for and their use in biosensing. Biosensors 2019, 9, 78. [CrossRef]

6. Rai, M.; Bonde, S.; Golinska, P.; Trzcińska-Wencel, J.; Gade, A.; Abd-Elsalam, K.A.; Shende, S.; Gaikwad, S.; Ingle, A.P. Fusarium as a novel fungus for the synthesis of nanoparticles: Mechanism and applications. J. Fungi 2021, 7, 139. [CrossRef] [PubMed]

7. Ahmad, S.; Munir, S.; Zeb, N.; Ullah, A.; Khan, B.; Ali, J.; Bilal, M.; Omer, M.; Alamzeb, M.; Salman, S.M.; et al. Green nanotechnology: A review on green synthesis of silver nanoparticles-An ecofriendly approach. Int. J. Nanomed. 2019, 14, 5087-5107. [CrossRef]

8. Castillo-Henríquez, L.; Alfaro-Aguilar, K.; Ugalde-Álvarez, J.; Vega-Fernández, L.; Montes de Oca-Vásquez, G.; Vega-Baudrit, J.R. Green synthesis of gold and silver nanoparticles from plant extracts and their possible applications as antimicrobial agents in the agricultural area. Nanomaterials 2020, 10, 1763. [CrossRef]

9. Wypij, M.; Jędrzejewski, T.; Trzcińska-Wencel, J.; Ostrowski, M.; Rai, M.; Golińska, P. Green synthesized silver nanoparticles: Antibacterial and anticancer activities, biocompatibility, and analyses of surface-attached proteins. Front. Microbiol. 2021, 12, 632505. [CrossRef]

10. Rai, M.; Yadav, A.; Gade, A. Silver nanoparticles as a new generation of antimicrobials. Biotechnol. Adv. 2009, 27, 76-83. [CrossRef]

11. Klaus, A.; Petrovic, P.; Vunduk, J.; Pavlovic, V.; Van Griensven, L.J.L.D. The antimicrobial activities of silver nanoparticles synthesized from medicinal mushrooms. Int. J. Med. Mushrooms 2020, 22, 869-883. [CrossRef] [PubMed]

12. Kuppusamy, P.; Yusoff, M.M.; Maniam, G.P.; Govindan, N. Biosynthesis of metallic nanoparticles using plant derivatives and their new avenues in pharmacological applications- an updated report. Saudi Pharm. J. 2016, 24, 473-483. [CrossRef]

13. Saravanan, A.; Kumar, P.S.; Karishma, S.; Vo, D.N.; Jeevanantham, S.; Yaashikaa, P.R.; George, C.S. A review on biosynthesis of metal nanoparticles and its environmental applications. Chemosphere 2021, 264, 128580. [CrossRef]

14. Singh, J.; Datta, T.; Kim, K.H.; Rawat, M.; Samddar, P.; Kumar, P. Green synthesis of metals and their oxide nanoparticles: Applications for environmental remediation. J. Nanobiotechnol. 2018, 16, 84. [CrossRef]

15. Iravani, S.; Korbekandi, H.; Mirmohammadi, S.V.; Zolfaghari, B. Synthesis of silver nanoparticles: Chemical, physical and biological methods. Res. Pharm. Sci. 2014, 9, 385-406. [PubMed]

16. Bilal, M.; Rasheed, T.; Iqbal, H.M.N.; Hu, H.; Zhang, X. Silver nanoparticles: Biosynthesis and antimicrobial potentialities. Int. J. Pharmacol. 2017, 13, 832-845. [CrossRef]

17. Ibrahim, E.; Fouad, H.; Zhang, M.; Zhang, Y.; Qiu, W.; Yan, C.; Li, B.; Mo, J.; Chen, J. Biosynthesis of silver nanoparticles using endophytic bacteria and their role in inhibition of rice pathogenic bacteria and plant growth promotion. RSC Adv. 2019, 9, 29293. [CrossRef]

18. Mondol, A.H.; Yadav, D.; Mitra, S.; Mukhopadhyay, K. Biosynthesis of silver nanoparticles using culture supernatant of Shewanella sp. ARY1 and their antibacterial activity. Int. J. Nanomed. 2020, 15, 8295-8310. [CrossRef] [PubMed]

19. Shakhatreh, M.A.K.; Al-Rawi, O.F.; Swedan, S.F.; Alzoubi, K.H.; Khabour, O.F.; Al-Fand, M. Biosynthesis of silver nanoparticles from Citrobacter freundii as antibiofilm agents with their cytotoxic effects on human cells. Curr. Pharm. Biotechnol. 2021, 22, 1254-1263. [CrossRef] [PubMed]

20. Singh, Y.; Kaushal, S.; Sodhi, R.S. Biogenic synthesis of silver nanoparticles using cynaobacterium Leptolyngbya sp. WUC 59 cell-free extract and their effects on bacterial growth and seed germination. Nanoscale Adv. 2020, 2, 3972-3982. [CrossRef]

21. Sulaiman, G.M.; Hussein, T.H.; Saleem, M.M. Biosynthesis of silver nanoparticles synthesized by Aspergillus flavus and their anti-oxidant, antimicrobial and cytotoxicity properties. Bull. Mater. Sci. 2015, 38, 639-644. [CrossRef]

22. Guilger-Casagrande, M.; Germano-Costa, T.; Pasquoto-Stigliani, T.; Fraceto, L.F.; De Lima, R. Biosynthesis of silver nanoparticles employing Trichoderma harzianum with enzymatic stimulation for the control of Scleotinia sclerotiorum. Sci. Rep. 2019, 9, 14351. [CrossRef] [PubMed]

23. Bhatnagar, S.; Kobori, T.; Ganesh, D.; Ogawa, K.; Aoyagi, H. Biosynthesis of Silver Nanoparticles Mediated by Extracellular Pigment from Talaromyces purpurogenus and Their Biomedical Applications. Nanomaterials 2019, 9, 1042. [CrossRef]

24. Rodriguez-Serrano, C.; Guzman-Moreno, J.; Angelez-Chavez, C.; Rodriguez-Gonzalez, V.; Ortega-Sigala, J.J.; Ramírez-Santoyo, R.M.; Vidales-Rodríguez, L.E. Biosynthesis of silver nanoparticles by Fusarium scirpi and its potential as an antimicrobial agent against uropathogenic Escherchia coli biofilms. PLoS ONE 2020, 15, e0230275. [CrossRef] 
25. Mohanta, Y.K.; Panda, S.K.; Bastia, A.K.; Mohanta, T.K. Biosynthesis of silver nanoparticles from Protium serratum and investigation of their potential impacts on food safety and control. Front. Microbiol. 2017, 8, 626. [CrossRef]

26. Khan, M.; Khan, A.U.; Alam, M.J.; Park, S.; Alam, M. Biosynthesis of silver nanoparticles and its application against phytopathogenic bacterium and fungus. Int. J. Environ. Anal. Chem. 2019, 100, 1390-1401. [CrossRef]

27. Sila, M.J.; Nyambura, M.I.; Abongo, D.A.; Mwaura, F.B.; Iwuoha, E. Biosynthesis of silver nanoparticles from Eucalyptus corymbia leaf extract at optimized conditions. Nanohybrids Compos. 2019, 25, 32-45. [CrossRef]

28. Garibo, D.; Borbon-Nunez, H.A.; Diaz Le Leon, J.N.; Mendoza, E.G.; Estrada, I.; Toledano-Magaña, Y.; Tiznado, H.; OvalleMarroquin, M.; Soto-Ramos, A.G.; Blanco, A.; et al. Green synthesis of silver nanoparticles using Lysiloma acapulsensis exhibits high antimicrobial activity. Sci. Rep. 2020, 10, 12805. [CrossRef] [PubMed]

29. Kratošová, G.; Holišová, V.; Konvičková, Z.; Ingle, P.I.; Gaikwad, S.; Škrlová, K.; Prokop, A.; Rai, M.; Plachá, D. From biotechnology principles to functional and low-cost metallic bionanocatalysts. Biotechnol. Adv. 2019, 37, 154-176. [CrossRef] [PubMed]

30. Suriya, J.; Bharathi Raja, S.; Sekar, V.; Rajasekaran, R. Biosynthesis of silver nanoparticles and its antibacterial activity using seaweed Urospora sp. Afr. J. Biotechnol. 2012, 11, 12192-12198. [CrossRef]

31. Benakashani, F.; Allafchian, A.R.; Jalali, S.A.H. Biosnthesis of silver nanoparticles using Capparis spinosa L. extract and their antibacterial activity. Karbala Int. J. Mod. Sci. 2016, 2, 251-258. [CrossRef]

32. Elamawi, R.M.; Al-Harbi, R.E.; Hendi, A.A. Biosynthesis and characterization of silver nanoparticles using Trichoderma longibrachiatum and their effect on phytopathogenic fungi. Egypt. J. Biol. Pest Control 2018, 28, 28. [CrossRef]

33. Soares, M.R.P.; Correa, R.O.; Stroppa, P.F.H.; Marques, F.C.; Andrade, G.F.S.; Correa, C.C.; Brandao, M.A.F.; Raposo, N.R.B Biosynthesis of silver nanoparticles using Caesalpinia ferrera (Tul.) Martius extract: Physicochemical characterization, antifungal activity and cytotoxicity. PeerJ 2018, 6, e4361. [CrossRef]

34. Duraisamy, K.; Han, J.H.; Park, W.S.; Lee, S.M.; Wahab, R.; Lee, Y.S. Green biosynthesis of silver nanoparticles using Torreya nucifera and their antibacterial activity. Arab. J. Chem. 2019, 12, 1722-1732. [CrossRef]

35. Othman, A.M.; Elsayed, M.A.; Al-Balakocy, N.G.; Hassan, M.M.; Elshafei, A.M. Biosynthesis and characterization of silver nanoparticles induced by fungal proteins and its application in different biological activities. J. Genet. Eng. Biotechnol. 2019, 17, 8. [CrossRef]

36. Sedaghat, S.; Omidi, S. Batch process biosynthesis of silver nanoparticles using Equisetum arvense leaf extract. Bioinspired Biomim. Nanobiomater. 2019, 8, 190-197. [CrossRef]

37. Hemlata; Meena, P.R.; Singh, A.P.; Tejavath, K.K. Biosynthesis of silver nanoparticles using Cucumis prophetarum aqueous leaf extract and their antibacterial and antiproliferative activity against cancer cell lines. ACS Omega 2020, 5, 5520-5528. [CrossRef]

38. Fathy, W.; Elsayed, K.; Essawy, E.; Tawfik, E.; Zaki, A.; Abdelhameed, M.S.; Hammouda, O. Biosynthesis of silver nanoparticles from Synechocystis sp. to be used as a flocculant agent with different microalgae strains. Curr. Nanomater. 2020, 5, $175-187$. [CrossRef]

39. Wang, D.; Xue, B.; Wang, L.; Zhang, Y.; Liu, L.; Zhou, Y. Fungus-mediated green synthesis of nano-silver using Aspergillus sydowii and its antifungal/antiproliferative activities. Sci. Rep. 2021, 11, 10356. [CrossRef]

40. Yadav, A.; Kon, K.; Kratosova, G.; Duran, N.; Ingle, A.P.; Rai, M. Fungi as an efficient mycosystem for the synthesis of metal nanoparticles: Progress and key aspects of research. Biotechnol. Lett. 2015, 37, 2099-2120. [CrossRef] [PubMed]

41. Guilger-Casagrande, M.; de Lima, R. Synthesis of silver nanoparticles mediated by Fungi: A Review. Front. Bioeng. Biotechnol. 2019, 7, 287. [CrossRef]

42. Zimmerman, W.B.J. Microfluidics: History, Theory and Applications; Zimmerman, W.B.J., Ed.; CISM International Centre for Mechanical Sciences: Udine, Italy; Springer Science \& Business Media: Berlin/Heidelberg, Germany, 2006.

43. Dallinger, D.; Kappe, C.O. Why flow means green-Evaluating the merits of continuous processing in the context of sustainability. Curr. Opin. Green Sustain. Chem. 2017, 7, 6-12. [CrossRef]

44. Song, Y.; Hormes, J.; Kumar, C.S.S.R. Microfluidic synthesis of nanomaterials. Small 2008, 4, 698-711. [CrossRef] [PubMed]

45. Xu, L.; Peng, J.; Yan, M.; Zhang, D.; Shen, A.Q. Droplet synthesis of silver nanoparticles by a microfluidic device. Chem. Eng. Process 2016, 102, 186-193. [CrossRef]

46. Liu, H.; Huang, J.; Sun, D.; Lin, L.; Lin, W.; Li, J.; Jiang, X.; Wu, W.; Li, Q. Microfluidic biosynthesis of silver nanoparticles: Effect of process parameters on size distribution. Chem. Eng. J. 2012, 209, 568-576. [CrossRef]

47. Liu, H.; Huang, J.; Sun, D.; Odoom-Wubah, T.; Li, J.; Li, Q. Continuous-flow biosynthesis of Au-Ag bimetallic nanoparticles in a microreactor. J. Nanopart. Res. 2014, 16, 2698. [CrossRef]

48. Hamouda, R.A.; Hussein, M.H.; Abo-elmagd, R.A.; Bawazir, S.S. Synthesis and biological characterization of silver nanoparticles derived from the cyanobacterium Oscillatoria limnetica. Sci. Rep. 2019, 9, 13071. [CrossRef]

49. Vanlalveni, C.; Lallianrawna, S.; Biswas, A.; Selvaraj, M.; Changmai, B.; Rokhum, S.L. Green synthesis of silver nanoparticles using plant extracts and their antimicrobial activities: A review of recent literature. RSC Adv. 2021, 11, 2804-2837. [CrossRef]

50. Song, J.Y.; Kim, B.S. Rapid biological synthesis of silver nanoparticles using plant leaf extracts. Bioprocess Biosyst. Eng. 2009, 32, 79-84. [CrossRef] [PubMed]

51. Ahmed, S.; Ahmad, M.; Swami, B.L.; Ikram, S. A review on plants extract mediated synthesis of silver nanoparticles for antimicrobial applications: A green expertise. J. Adv. Res. 2016, 7, 17-28. [CrossRef] [PubMed]

52. Velusamy, P.; Kumar, G.V.; Jeyanthi, V.; Das, J.; Pachaiappan, R. Bio-inspired green nanoparticles: Synthesis, mechanism, and antibacterial application. Toxicol. Res. 2016, 32, 95-102. [CrossRef] 
53. Hietzschold, S.; Walter, A.; Davis, C.; Taylor, A.A.; Sepunaru, L. Does nitrate reductase play a role in silver nanoparticle synthesis? Evidence for NADPH as the sole reducing agent. ACS Sustain. Chem. Eng. 2019, 7, 8070-8076. [CrossRef]

54. Garg, D.; Sarkar, A.; Chand, P.; Bansal, P.; Gola, D.; Sharma, S.; Khantwal, S.; Mehrotra, S.A.; Chauhan, N.; Bharti, R.K. Synthesis of silver nanoparticles utilizing various biological systems: Mechanisms and applications: A review. Prog. Biomater. 2020, 9, 81-95. [CrossRef] [PubMed]

55. Mikhailova, E.O. Silver Nanoparticles: Mechanism of Action and Probable Bio-Application. J. Funct. Biomater. 2020, 11, 84. [CrossRef] [PubMed]

56. Mokhtari, N.; Daneshpajouh, S.; Seyedbagheri, S.; Atashdehghan, R.; Abdi, K.; Sarkar, S.; Minaian, S.; Shahverdi, H.R.; Shahverdi, A.R. Biological synthesis of very small silver nanoparticles by culture supernatant of Klebsiella pneumonia: The effects of visiblelight irradiation and the liquid mixing process. Mater. Res. Bull. 2009, 44, 1415-1421. [CrossRef]

57. Natarajan, K.; Selvaraj, S.; Murty, V.R. Microbial production of silver nanoparticles. Dig. J. Nanomater. Biostructures 2010, 5 , 135-140.

58. Otari, S.; Patil, R.; Nadaf, N.; Ghosh, S.; Pawar, S. Green biosynthesis of silver nanoparticles from an actinobacteria Rhodococcus sp. Mater. Lett. 2012, 72, 92-94. [CrossRef]

59. Chauhan, R.; Kumar, A.; Abraham, J. A biological approach to synthesis of silver nanoparticles with Streptomyces sp. JAR1 and its antimicrobial activity. Sci. Pharm. 2013, 81, 607-621. [CrossRef] [PubMed]

60. Singh, R.; Wagh, P.; Wadhwani, S.; Gaidhani, S.; Kumbhar, A.; Bellare, J.; Chopade, B.A. Synthesis, optimization, and characterization of silver nanoparticles from Acinetobacter calcoaceticus and their enhanced antibacterial activity when combined with antibiotics. Int. J. Nanomed. 2013, 8, 4277-4290. [CrossRef]

61. Rajeshkumar, S.; Malarkodi, C. In vitro antibacterial activity and mechanism of silver nanoparticles against foodborne pathogens. Bioinorg. Chem. Appl. 2014, 4, 581890. [CrossRef]

62. Elbeshehy, E.K.; Elazzazy, A.M.; Aggelis, G. Silver nanoparticles synthesis mediated by new isolates of Bacillus spp., nanoparticle characterization and their activity against bean yellow mosaic virus and human pathogens. Front. Microbiol. 2015, 6, 453. [CrossRef] [PubMed]

63. Zhang, H.; Li, Q.; Lu, Y.; Sun, D.; Lin, X.; Deng, X.; He, N.; Zheng, S. Biosorption and bioreduction of diamine silver complex by Corynebacterium. J. Chem. Technol. Biotechnol. 2005, 80, 285-290. [CrossRef]

64. Klaus, T.; Joerger, R.; Olsson, E.; Granqvist, C.G. Silver-based crystalline nanoparticles, microbially fabricated. Proc. Natl. Acad. Sci. USA 1999, 96, 13611-13614. [CrossRef]

65. El-Baghdady, K.Z.; El-Shatoury, E.H.; Abdullah, O.M.; Khalil, M.M.H. Biogenic production of silver nanoparticles by Enterobacter cloacae Ism26. Turk. J. Biol. 2018, 42, 319-328. [CrossRef]

66. Ghashghaei, S.; Emtiazi, G. The methods of nanoparticle synthesis using bacteria as biological nanofactories, their mechanisms and major applications. Curr. Bionanotechnol. 2015, 1, 3-17. [CrossRef]

67. Wang, F.; Liu, B.; Huang, P.J.; Liu, J. Rationally designed nucleobase and nucleotide coordinated nanoparticles for selective DNA adsorption and detection. Anal. Chem. 2013, 85, 12144-12151. [CrossRef] [PubMed]

68. Jeevan, P.; Ramya, K.; Edith Rena, A. Extracellular biosynthesis of silver nanoparticles by culture supernatant of Pseudomonas Aeruginosa. Indian J. Biotechnol. 2012, 11, 72-76.

69. Luo, K.; Jung, S.; Park, K.H.; Kim, Y.R. Microbial biosynthesis of silver nanoparticles in different culture media. J. Agric. Food Chem. 2018, 66, 957-962. [CrossRef]

70. Naik, R.R.; Stringer, S.J.; Agarwal, G.; Jones, S.E.; Stone, M.O. Biomimetic synthesis and patterning of silver nanoparticles. Nat. Mater. 2002, 1, 169-172. [CrossRef]

71. Nam, H.Y.; Hahn, H.J.; Nam, K.; Choi, W.H.; Jeong, Y.; Kim, D.E.; Park, J.S. Evaluation of generations 2, 3 and 4 arginine modified PAMAM dendrimers for gene delivery. Int. J. Pharm. 2008, 363, 199-205. [CrossRef] [PubMed]

72. Graf, P.; Mantion, A.; Foelske, A.; Shkilnyy, A.; Masic, A.; Thunemann, A.F.; Taubert, A. Peptide-coated silver nanoparticles: Synthesis, surface chemistry, and pH-triggered, reversible assembly into particle assemblies. Chemistry 2009, 15, 5831-5844. [CrossRef]

73. Crookes-Goodson, W.J.; Slocik, J.M.; Naik, R.R. Bio-directed synthesis and assembly of nanomaterials. Chem. Soc. Rev. 2008, 37, 2403-2412. [CrossRef]

74. Ahmad, A.; Mukherjee, P.; Senapati, S.; Mandal, D.; Khan, M.I.; Kumar, R.; Sastry, M. Extracellular biosynthesis of silver nanoparticles using the fungus Fusarium oxysporum. Colloids Surf. B 2003, 28, 313-318. [CrossRef]

75. Ingle, A.; Gade, A.; Pierrat, S.; Sonnichsen, C.; Rai, M. Mycosynthesis of silver nanoparticles using the fungus Fusarium acuminatum and its activity against some human pathogenic bacteria. Curr. Nanosci. 2008, 4, 141-144. [CrossRef]

76. Durán, N.; Marcato, P.D.; Alves, O.L.; DeSouza, G.H.I.; Esposito, E. Mechanistic aspects of biosynthesis of silver nanoparticles by several Fusarium oxysporum strains. J. Nanobiotechnol. 2005, 3, 8. [CrossRef] [PubMed]

77. Kumar, S.A.; Abyaneh, M.K.; Gosavi, S.W.; Kulkarni, S.K.; Pasricha, R.; Ahmad, A.; Khan, M.I. Nitrate reductase-mediated synthesis of silver nanoparticles from $\mathrm{AgNO}_{3}$. Biotechnol. Lett. 2007, 29, 439-445. [CrossRef]

78. Li, G.; He, D.; Qian, Y.; Guan, B.; Gao, S.; Cui, Y.; Yokoyama, K.; Wang, L. Fungus-mediated green synthesis of silver nanoparticles using Aspergillus terreus. Int. J. Mol. Sci. 2012, 13, 466-476. [CrossRef] [PubMed] 
79. Mukherjee, P.; Roy, M.; Mandal, B.P.; Dey, G.K.; Mukherjee, P.K.; Ghatak, J.; Tyagi, A.K.; Kale, S.P. Green synthesis of highly stabilized nanocrystalline silver particles by a nonpathogenic and agriculturally important fungus T. asperellum. Nanotechnology 2008, 19, 103-110. [CrossRef] [PubMed]

80. Sanghi, R.; Verma, P. Biomimetic synthesis and characterization of protein capped silver nanoparticles. Bioresour. Technol. 2009, 100, 502-504. [CrossRef] [PubMed]

81. Vetchinkina, E.; Loshchinina, E.; Kupryashina, M.; Burov, A.; Pylaev, T.; Nikitina, V. Green synthesis of nanoparticles with extracellular and intracellular extracts of basidiomycetes. Peer] 2018, 6, e5237. [CrossRef]

82. Mukherjee, P.; Ahmad, A.; Mandal, D.; Senapati, S.; Sainkar, S.R.; Khan, M.I.; Ramani, R.; Parischa, R.; Ajayakumar, P.V.; Alam, M.; et al. Bioreduction of $\mathrm{AuCl}^{4-}$ ions by the fungus Verticillium sp. and surface trapping of the gold nanoparticles formed. Angew. Chem. Int. Ed. 2001, 40, 3585-3588. [CrossRef]

83. Riddin, T.L.; Gericke, M.; Whiteley, C.G. Analysis of the inter- and extracellular formation of platinum nanoparticles by Fusarium oxysporum $\mathrm{f}$ sp. lycopersici using response surface methodology. Nanotechnology 2006, 17, 3482-3489. [CrossRef] [PubMed]

84. Mittal, J.; Jain, R.; Sharma, M.M. Phytofabrication of nanoparticles through plant as nanofactories. Adv. Nat. Sci. Nanosci. Nanotechnol. 2014, 5, 043002. [CrossRef]

85. Arshad, H.; Sami, M.A.; Sadaf, S.; Hassan, U. Salvadora persica mediated synthesis of silver nanoparticles and their antimicrobial efficacy. Sci. Rep. 2021, 11, 5996. [CrossRef]

86. Dauthal, P.; Mukhopadhyay, M. Noble metal nanoparticles: Plant-mediated synthesis, mechanistic aspects of synthesis, and applications. Ind. Eng. Chem. Res. 2016, 55, 9557-9577. [CrossRef]

87. Aljabali, A.A.A.; Akkam, Y.; Al Zoubi, M.S.; Al-Batayneh, K.M.; Al-Trad, B.; Abo Alrob, O.; Alkilany, A.M.; Benamara, M.; Evans, D.J. Synthesis of Gold Nanoparticles Using Leaf Extract of Ziziphus zizyphus and their Antimicrobial Activity. Nanomaterials 2018, 8, 174. [CrossRef]

88. Shankar, S.S.; Ahmad, A.; Sastry, M. Geranium leaf assisted biosynthesis of silver nanoparticles. Biotechnol. Prog. 2003, 19, 1627-1631. [CrossRef] [PubMed]

89. Shankar, S.S.; Rai, A.; Ahmad, A.; Sastry, M. Rapid synthesis of Au, Ag, and bimetallic Au core-Ag shell nanoparticles using Neem (Azadirachta indica) leaf broth. J. Colloid Interface Sci. 2004, 275, 496-502. [CrossRef] [PubMed]

90. Ahmad, N.; Sharma, S.; Alam, M.K.; Singh, V.N.; Shamsi, S.F.; Mehta, B.R.; Fatma, A. Rapid synthesis of silver nanoparticles using dried medicinal plant of basil. Colloids Surf. B. 2010, 81, 81-86. [CrossRef] [PubMed]

91. Vanaja, M.; Annadurai, G. Coleus aromaticus leaf extract mediated synthesis of silver nanoparticles and its bactericidal activity. Appl. Nanosci. 2012, 3, 217-223. [CrossRef]

92. Gardea-Torresdey, J.L.; Parsons, J.G.; Gomez, E.; Peralta-Videa, J.R.; Troiani, H.E.; Santiago, P.; Jose-Yacaman, M. Formation and growth of Au nanoparticles inside live Alfalfa plants. Nano Lett. 2002, 2, 397-401. [CrossRef]

93. Xia, Y.; Xia, X.; Peng, H.C. Shape-controlled synthesis of colloidal metal nanocrystals: Thermodynamic versus kinetic products. J. Am. Chem. Soc. 2015, 137, 7947-7966. [CrossRef] [PubMed]

94. El-Rafie, M.H.; El-Naggar, M.E.; Ramadan, M.A.; Fouda, M.M.G.; Al-Dey, S.S.; Hebeish, A. Environmental synthesis of silver nanoparticles using hydroxypropyl starch and their characterization. Carbohydr. Polym. 2011, 86, 630-635. [CrossRef]

95. Roy, A.; Bulut, O.; Some, S.; Kumar Mandal, A.; Yilmaz, M.D. Green synthesis of silver nanoparticles: Biomolecule-nanoparticle organizations targeting antimicrobial activity. RSC Adv. 2019, 9, 2673-2702. [CrossRef]

96. Ingle, A.; Rai, M.; Gade, A.; Bawaskar, M. Fusarium solani: A novel biological agent for the extracellular synthesis of silver nanoparticles. J. Nanopart. Res. 2009, 11, 2079-2085. [CrossRef]

97. Kowalczyk, B.; Lagzi, I.; Grzybowski, B.A. Nanoseparations: Strategies for size and/or shape-selective purification of nanoparticles. Curr. Opin. Colloid Interface Sci. 2011, 16, 135-148. [CrossRef]

98. Ashrafi, S.J.; Rastegar, M.F.; Ashrafi, M.; Yazdian, F.; Pourrahim, R.; Suresh, A.K. Influence of external factors on the production and morphology of biogenic silver nanocrystallites. J. Nanosci. Nanotechnol. 2013, 13, 2295-2301. [CrossRef]

99. Qidwai, A.; Pandey, A.; Kumar, R.; Shukla, S.K.; Dikshit, A. Advances in biogenic nanoparticles and the mechanisms of antimicrobial effects. Indian J. Pharm. Sci. 2018, 80, 592-603. [CrossRef]

100. Yahyaei, B.; Pourali, P. One step conjugation of some chemotherapeutic drugs to the biologically produced gold nanoparticles and assessment of their anticancer effects. Sci. Rep. 2019, 9, 10242. [CrossRef]

101. John, M.S.; Nagoth, J.A.; Ramasamy, K.P.; Mancini, A.; Giuli, G.; Natalello, A.; Ballarini, P.; Miceli, C.; Pucciarelli, S. Synthesis of bioactive silver nanoparticles by a Pseudomonas strain associated with the Antarctic psychrophilic protozoon Euplotes focardii. Mar. Drugs 2020, 18, 38. [CrossRef]

102. Netala, V.R.; Kotakadi, V.S.; Domdi, L.; Gaddam, S.A.; Bobbu, P.; Venkata, S.K.; Ghosh, S.B.; Tartte, V. Biogenic silver nanoparticles: Efficient and effective antifungal agents. Appl. Nanosci. 2016, 6, 475-484. [CrossRef]

103. Datkhile, K.D.; Durgawale, P.P.; Patil, M.N. Biogenic silver nanoparticles are equally cytotoxic as chemically synthesized silver nanoparticles. Biomed. Pharmacol. J. 2017, 10, 337-344. [CrossRef]

104. Gurunathan, S.; Kalishwaralal, K.; Vaidyanathan, R.; Venkataraman, D.; Pandian, S.R.; Muniyandi, J.; Hariharan, N.; Eom, S.H. Biosynthesis, purification and characterization of silver nanoparticles using Escherichia coli. Colloids Surf. B Biointerfaces 2009, 74, 328-335. [CrossRef] [PubMed]

105. Schröfel, A.; Kratošová, G.; Šafařík, I.; Šafaříková, M.; Raška, I.; Shor, L.M. Applications of biosynthesized metallic nanoparticlesA review. Acta Biomater. 2014, 10, 4023-4042. [CrossRef] 
106. Thiruvengadam, M.; Rajakumar, G.; Chung, I.M. Nanotechnology: Current uses and future applications in the food industry. 3 Biotech 2018, 8, 74. [CrossRef]

107. Xu, L.; Wang, Y.Y.; Huang, J.; Chen, C.Y.; Wang, Z.X.; Xie, H. Silver nanoparticles: Synthesis, medical applications and biosafety. Theranostics 2020, 10, 8996. [CrossRef] [PubMed]

108. Prathna, T.C.; Chandrasekaran, N.; Raichur, A.M.; Mukherjee, A. Kinetic evolution studies of silver nanoparticles in a bio-based green synthesis process. Colloids Surf. A Physicochem. Eng. Asp. 2011, 377, 212-216. [CrossRef]

109. Ma, R.; Levard, C.; Marinakos, S.M.; Cheng, Y.; Liu, J.; Michel, F.M.; Lowry, G.V. Size-controlled dissolution of organic-coated silver nanoparticles. Environ. Sci. Technol. 2012, 46, 752-759. [CrossRef] [PubMed]

110. Gurunathan, S.; Jeong, J.K.; Han, J.W.; Zhang, X.F.; Park, J.H.; Kim, J.H. Multidimensional effects of biologically synthesized silver nanoparticles in Helicobacter pylori, Helicobacter felis, and human lung (L132) and lung carcinoma A549 cells. Nanoscale Res. Lett. 2015, 10, 35. [CrossRef]

111. Vigneshwaran, N.; Ashtaputre, N.M.; Varadarajan, P.V.; Nachane, R.P.; Paralikar, K.M.; Balasubramanian, R.H. Biological synthesis of silver nanoparticles using the fungus Aspergillus flavus. Mater. Lett. 2007, 61, 1413-1418. [CrossRef]

112. Fenfen, L.Ü.; Yixian, G.A.O.; Huang, J.; Daohua, S.; Qingbiao, L.I. Roles of biomolecules in the biosynthesis of silver nanoparticles: Case of Gardenia jasminoides extract. Chin. J. Chem. Eng. 2014, 22, 706-712. [CrossRef]

113. Haggag, E.G.; Elshamy, A.M.; Rabeh, M.A.; Gabr, N.M.; Salem, M.; Youssif, K.A.; Abdelmohsen, U.R. Antiviral potential of green synthesized silver nanoparticles of Lampranthuscoc cineus and Malephora lutea. Int. J. Nanomed. 2019, 14, 6217. [CrossRef] [PubMed]

114. Mujaddidi, N.; Nisa, S.; Al Ayoubi, S.; Bibi, Y.; Khan, S.; Sabir, M.; Qayyum, A. Pharmacological properties of biogenically synthesized silver nanoparticles using endophyte Bacillus cereus extract of Berberis lyceum against oxidative stress and pathogenic multidrug-resistant bacteria. Saudi J. Biol. Sci. 2021, 28, 6432-6440. [CrossRef]

115. Rai, M.; Golińska, P. Microbial Nanotechnology; CRC Press: Boca Raton, FL, USA; Taylor and Francis Group: Boca Raton, FL, USA, 2020.

116. Golińska, P.; Wypij, M.; Ingle, A.P.; Gupta, I.; Dahm, H.; Rai, M. Biogenic synthesis of metal nanoparticles from actinomycetes: Biomedical applications and cytotoxicity. Appl. Microbiol. Biotechnol. 2014, 98, 8083-8097. [CrossRef]

117. Yetisgin, A.A.; Cetinel, S.; Zuvin, M.; Kosar, A.; Kutlu, O. Therapeutic Nanoparticles and Their Targeted Delivery Applications. Molecules 2020, 25, 2193. [CrossRef] [PubMed]

118. Lee, W.; Kim, K.; Lee, D.G. A novel mechanism for the antibacterial effect of silver nanoparticles on Escherichia coli. Biometals 2014, 27, 1191-1201. [CrossRef] [PubMed]

119. Fernández, J.G.; Fernández-Baldo, M.A.; Berni, E.; Camí, G.; Durán, N.; Raba, J.; Sanz, M.I. Production of silver nanoparticles using yeasts and evaluation of their antifungal activity against phytopathogenic fungi. Process Biochem. 2016, 51, 1306-1313. [CrossRef]

120. Ebrahimi, A.; Jafferi, H.; Habibian, S.; Lotfalian, S. Evaluation of anti biofilm and antibiotic potentiation activities of silver nanoparticles against some nosocomial pathogens. Iran. J. Pharm. Sci. 2018, 14, 7-14. [CrossRef]

121. Fanti, J.R.; Tomiotto-Pellissier, F.; Miranda-Sapla, M.M.; Cataneo, A.H.D.; Andrade, C.G.T.J.; Panis, C.; Rodrigues, J.H.D.S.; Wowk, P.F.; Kuczera, D.; Costa, I.N.; et al. Biogenic silver nanoparticles inducing Leishmania amazonensis promastigote and amastigote death in vitro. Acta Trop. 2018, 178, 46-54. [CrossRef]

122. Abdel-Aziz, M.M.; Emam, T.M.; Elsherbiny, E.A. Bioactivity of magnesium oxide nanoparticles synthesized from cell filtrate of endobacterium Burkholderia rinojensis against Fusarium oxysporum. Mater. Sci. Eng. C 2020, 109, 110617. [CrossRef]

123. Wypij, M.; Jędrzejewski, T.; Ostrowski, M.; Trzcińska, J.; Rai, M.; Golińska, P. Biogenic silver nanoparticles: Assessment of their cytotoxicity, genotoxicity and study of capping proteins. Molecules 2020, 25, 3022. [CrossRef] [PubMed]

124. Ajaz, S.; Ahmed, T.; Shahid, M.; Noman, M.; Shah, A.A.; Mehmood, M.A.; Li, B. Bioinspired green synthesis of silver nanoparticles by using a native Bacillus sp. strain AW1-2: Characterization and antifungal activity against Colletotrichum falcatum Went. Enzyme Microb. Technol. 2021, 144, 109745. [CrossRef]

125. Al-Kalifawi, E.J.; Al-Azzawi, Y.J.; Feaza, M.A. Antibacterial, antivirulence and antifungal activity of silver nanoparticles synthesized using alkhal mother shae. J. Phys. Conf. Ser. 2021, 1879, 022054. [CrossRef]

126. Franci, G.; Falanga, A.; Galdiero, S.; Palomba, L.; Rai, M.; Morelli, G.; Galdiero, M. Silver Nanoparticles as Potential Antibacterial Agents. Molecules 2015, 20, 8856-8874. [CrossRef]

127. Gopinath, P.M.; Narchonai, G.; Dhanasekaran, D. Mycosynthesis, characterization and antibacterial properties of AgNPs against multidrug resistant (MDR) bacterial pathogens of female infertility cases. Asian J. Pharm. Sci. 2015, 10, 138-145. [CrossRef]

128. Crisan, C.M.; Mocan, T.; Manolea, M.; Lasca, L.I.; Tăbăran, F.A.; Mocan, L. Review on Silver Nanoparticles as a Novel Class of Antibacterial Solutions. Appl. Sci. 2021, 11, 1120. [CrossRef]

129. Anasane, N.; Golińska, P.; Wypij, M.; Rathod, D.; Dahm, H.; Rai, M. Acidophilic actinobacteria synthesised silver nanoparticles showed remarkable activity against fungi-causing superficial mycoses in humans. Mycoses 2016, 59, 157-166. [CrossRef]

130. Bakhtiari-Sardari, A.; Mashreghi, M.; Eshghi, H.; Behnam-Rasouli, F.; Lashani, E.; Shahnavaz, B. Comparative evaluation of silver nanoparticles biosynthesis by two cold-tolerant Streptomyces strains and their biological activities. Biotechnol. Lett. 2020, 42, 1985-1999. [CrossRef] [PubMed]

131. Gurunathan, S. Rapid biological synthesis of silver nanoparticles and their enhanced antibacterial effects against Escherichia fergusonii and Streptococcus mutans. Arab. J. Chem. 2019, 12, 168-180. [CrossRef] 
132. Hossain, A.; Hong, X.; Ibrahim, E.; Li, B.; Sun, G.; Meng, Y.; Wang, Y.; An, Q. Green Synthesis of Silver Nanoparticles with Culture Supernatant of a Bacterium Pseudomonas rhodesiae and Their Antibacterial Activity against Soft Rot Pathogen Dickeya dadantii. Molecules 2019, 24, 2303. [CrossRef] [PubMed]

133. Divya, M.; Kiran, G.; Hassan, S.; Selvin, J. Biogenic Synthesis and Effect of Silver Nanoparticles (AgNPs) to Combat CatheterRelated Urinary Tract Infections. Biocatal. Agric. Biotechnol. 2019, 18, 101037. [CrossRef]

134. Saravanan, M.; Barik, S.K.; MubarakAli, D.; Prakash, P.; Pugazhendhi, A. Synthesis of silver nanoparticles from Bacillus brevis (NCIM 2533) and their antibacterial activity against pathogenic bacteria. Microb. Pathog. 2018, 116, 221-226. [CrossRef]

135. Dawoud, T.M.; Yassin, M.A.; El-Samawaty, A.R.M.; Elgorban, A.M. Silver nanoparticles synthesized by Nigrospora oryzae showed antifungal activity. Saudi J. Biol. Sci. 2021, 28, 1847-1852. [CrossRef] [PubMed]

136. Singh, T.; Jyoti, K.; Patnaik, A.; Singh, A.; Chauhan, R.; Chandel, S.S. Biosynthesis, characterization and antibacterial activity of silver nanoparticles using an endophytic fungal supernatant of Raphanus sativus. J. Genet. Eng. Biotechnol. 2017, 15, 31-39. [CrossRef]

137. Gond, S.K.; Mishra, A.; Verma, S.K.; Sharma, V.K.; Kharwar, R.N. Synthesis and characterization of antimicrobial silver nanoparticles by an endophytic fungus isolated from Nyctanthes arbor-tristis. Proc. Natl. Acad. Sci. India Sect. B Biol. Sci. 2020, 90, 641-645. [CrossRef]

138. Azmath, P.; Baker, S.; Rakshith, D.; Satish, S. Mycosynthesis of silver nanoparticles bearing antibacterial activity. Saudi Pharm. J. 2016, 24, 140-146. [CrossRef]

139. Rodrigues, A.G.; RdC, R.; Selari, P.J.R.G.; de Araujo, W.L.; de Souza, A.O. Anti-biofilm action of biological silver nanoparticles produced by Aspergillus tubingensis and antimicrobial activity of fabrics carrying it. Biointerface Res. Appl. Chem. 2021, 11, 14764-14774. [CrossRef]

140. Hulikere, M.M.; Joshi, C. Characterization, antioxidant and antimicrobial activity of silver nanoparticles synthesized using marine endophytic fungus- Cladosporium cladosporioides. Process Biochem. 2019, 82, 199-204. [CrossRef]

141. Khorrami, S.; Zarrabi, A.; Khaleghi, M.; Danaei, M.; Mozafari, M.R. Selective cytotoxicity of green synthesized silver nanoparticles against the MCF-7 tumor cell line and their enhanced antioxidant and antimicrobial properties. Int. J. Nanomed. 2018, $13,8013$. [CrossRef] [PubMed]

142. He, Y.; Du, Z.; Ma, S.; Cheng, S.; Jiang, S.; Liu, Y.; Zheng, X. Biosynthesis, antibacterial activity and anticancer effects against prostate cancer (PC-3) cells of silver nanoparticles using Dimocarpus Longan Lour. peel extract. Nanoscale Res. Lett. 2016, 11, 300. [CrossRef]

143. Wunnoo, S.; Paosen, S.; Lethongkam, S.; Sukkurd, R.; Waen-ngoen, T.; Nuidate, T.; Voravuthikunchai, S.P. Biologically rapid synthesized silver nanoparticles from aqueous Eucalyptus camaldulensis leaf extract: Effects on hyphal growth, hydrolytic enzymes, and biofilm formation in Candida albicans. Biotechnol. Bioeng. 2021, 118, 1578-1592. [CrossRef] [PubMed]

144. Chatterjee, T.; Chatterjee, B.K.; Majumdar, D.; Chakrabarti, P. Antibacterial effect of silver nanoparticles and the modeling of bacterial growth kinetics using a modified Gompertz model. Biochim. Biophys. Acta Gen. Subj. 2015, 1850, 299-306. [CrossRef] [PubMed]

145. Aghajanyan, A.; Gabrielyan, L.; Schubert, R.; Trchounian, A. Silver ion bioreduction in nanoparticles using Artemisia annua L. extract: Characterization and application as antibacterial agents. AMB Express 2020, 10, 66. [CrossRef]

146. Hambardzumyan, S.; Sahakyan, N.; Petrosyan, M.; Nasim, M.J.; Jacob, C.; Trchounian, A. Origanum vulgare L. extract-mediated synthesis of silver nanoparticles, their characterization and antibacterial activities. AMB Express 2020, 10, 162. [CrossRef] [PubMed]

147. Wypij, M.; Świecimska, M.; Czarnecka, J.; Dahm, H.; Rai, M.; Golinska, P. Antimicrobial and cytotoxicactivity of silvernanoparticlessynthesized from twohaloalkaliphilicactinobacterialstrainsalone and in combination with antibiotics. J. Appl. Microbiol. 2018, 124, 1411-1424. [CrossRef]

148. Kim, K.J.; Sung, W.S.; Moon, S.K.; Choi, J.S.; Kim, J.G.; Lee, D.G. Antifungal effect of silver nanoparticles on dermatophytes. J. Microbiol. Biotechnol. 2008, 18, 1482-1484.

149. Hassanab, A.A.; Mansourb, M.K.; Mahmoud, H.H. Biosynthesis of silver nanoparticles (Ag-Nps) (a model of metals) by Candida albicans and its antifungal activity on some fungal pathogens (Trichophyton mentagrophytes and Candida albicans). N. Y. Sci. J. 2013, 6, 27-34.

150. Joshi, P.A.; Bonde, S.R.; Gaikwad, S.C.; Joshi, P.A.; Bonde, S.R.; Gaikwad, S.C.; Gade, A.K.; Abd-Elsalam, K.; Rai, M.K. Comparative studies on synthesis of silver nanoparticles by Fusarium oxysporum and Macrophomina phaseolina and its efficacy against bacteria and Malassezia furfur. J. Bionanosci. 2013, 7, 378-385. [CrossRef]

151. Pereira, L.; Dias, N.; Carvalho, J.; Fernandes, S.; Santos, C.; Lima, N. Synthesis, characterization and antifungal activity of chemically and fungal-produced silver nanoparticles against Trichophyton rubrum. J. Appl. Microbiol. 2014, 117, 1601-1613. [CrossRef]

152. Thanighaiarassu, R.R.; BalwinNambikkairaj, R.D. Green synthesis of silver nanoparticles and characterization using plant leaf essential oil compound citral and their antifungal activity against human pathogenic fungi. J. Pharmacogn. Phytochem. 2018, 7 , 902-907.

153. Robles-Martínez, M.; González, J.F.C.; Pérez-Vázquez, F.J.; Montejano-Carrizales, J.M.; Pérez, E.; Patiño-Herrera, R. Antimycotic activity potentiation of Allium sativum extract and silver nanoparticles against Trichophyton rubrum. Chem. Biodivers. 2019, 16, e1800525. [CrossRef] [PubMed] 
154. Dutta, T.; Ghosh, N.N.; Das, M.; Adhikary, R.; Mandal, V.; Chattopadhyay, A.P. Green synthesis of antibacterial and antifungal silver nanoparticles using Citrus limetta peel extract: Experimental and theoretical studies. J. Environ. Chem. Eng. 2020, 8, 104019. [CrossRef]

155. Salleh, A.; Naomi, R.; Utami, N.D.; Mohammad, A.W.; Mahmoudi, E.; Mustafa, N.; Fauzi, M.B. The Potential of Silver Nanoparticles for Antiviral and Antibacterial Applications: A Mechanism of Action. Nanomaterials 2020, 10, 1566. [CrossRef] [PubMed]

156. Xia, Z.K.; Ma, Q.H.; Li, S.Y.; Zhang, D.Q.; Cong, L.; Tian, Y.L.; Yang, R.Y. The antifungal effect of silver nanoparticles on Trichosporon asahii. J. Microbiol. Immunol. Infect. 2016, 49, 182-188. [CrossRef] [PubMed]

157. Krishnaraj, C.; Jagan, E.G.; Rajasekar, S.; Selvakumar, P.; Kalaichelvan, P.T.; Mohan, N. Synthesis of silver nanoparticles using Acalypha indica leaf extracts and its antibacterial activity against water borne pathogens. Colloids Surf. B 2010, 76, 50-56. [CrossRef] [PubMed]

158. Kim, S.W.; Jung, J.H.; Lamsal, K.; Kim, Y.S.; Min, J.S.; Lee, Y.S. Antifungal effects of silver nanoparticles (AgNPs) against various plant pathogenic fungi. Mycobiology 2012, 40, 53-58. [CrossRef] [PubMed]

159. Lara, H.H.; Ayala-Núnez, N.V.; Turrent, L.D.C.I.; Padilla, C.R. Bactericidal effect of silver nanoparticles against multidrug-resistant bacteria. World J. Microbiol. Biotechnol. 2010, 26, 615-621. [CrossRef]

160. El-Rab, S.M.G.; Halawani, E.M.; Alzahrani, S.S. Biosynthesis of silver nano-drug using Juniperus excelsa and its synergistic antibacterial activity against multidrug-resistant bacteria for wound dressing applications. 3 Biotech 2021, 11, 255. [CrossRef]

161. Kumar, S.S.D.; Houreld, N.N.; Kroukamp, E.M.; Abrahamse, H. Cellular imaging and bactericidal mechanism of greensynthesized silver nanoparticles against human pathogenic bacteria. J. Photochem. Photobiol. B 2018, 178, 259-269. [CrossRef]

162. Escárcega-González, C.E.; Garza-Cervantes, J.A.; Vazquez-Rodríguez, A.; Montelongo-Peralta, L.Z.; Treviño-Gonzalez, M.T.; Castro, E.D.B.; Morones-Ramirez, J.R. In vivo antimicrobial activity of silver nanoparticles produced via a green chemistry synthesis using Acacia rigidula as a reducing and capping agent. Int. J. Nanomed. 2018, 13, 2349. [CrossRef]

163. Longhi, C.; Santos, J.P.; Morey, A.T.; Marcato, P.D.; Durán, N.; Pinge-Filho, P.; Yamauchi, L.M. Combination of fluconazole with silver nanoparticles produced by Fusarium oxysporum improves antifungal effect against planktonic cells and biofilm of drug-resistant Candida albicans. Sabouraudia 2015, 54, 428-432. [CrossRef]

164. Galdiero, S.; Falanga, A.; Vitiello, M.; Cantisani, M.; Marra, V.; Galdiero, M. Silver Nanoparticles as Potential Antiviral Agents. Molecules 2011, 16, 8894-8918. [CrossRef] [PubMed]

165. Akbarzadeh, A.; Kafshdooz, L.; Razban, Z.; Dastranj Tbrizi, A.; Rasoulpour, S.; Khalilov, R.; Kafshdooz, T. An overview application of silver nanoparticles in inhibition of herpes simplex virus. Artif. Cells Nanomed. Biotechnol. 2018, 46, $263-267$. [CrossRef] [PubMed]

166. Tortella, G.R.; Pieretti, J.C.; Rubilar, O.; Fernández-Baldo, M.; Benavides-Mendoza, A.; Diez, M.C.; Seabra, A.B. Silver, copper and copper oxide nanoparticles in the fight against human viruses: Progress and perspectives. Crit. Rev. Biotechnol. 2021, 7, 1-19. [CrossRef]

167. Avilala, J.; Golla, N. Antibacterial and antiviral properties of silver nanoparticles synthesized by marine Actinomycetes. Int. J. Pharm. Sci. Res. 2019, 10, 1223-1228. [CrossRef]

168. Sreekanth, T.V.M.; Nagajyothi, P.C.; Muthuraman, P.; Enkhtaivan, G.; Vattikuti, S.V.P.; Tettey, C.O.; Yoo, K. Ultra-sonicationassisted silver nanoparticles using Panax ginseng root extract and their anti-cancer and antiviral activities. J. Photochem. Photobiol. B 2018, 188, 6-11. [CrossRef] [PubMed]

169. Morris, D.; Ansar, M.; Speshock, J.; Ivanciuc, T.; Qu, Y.; Casola, A.; Garofalo, R.P. Antiviral and Immunomodulatory Activity of Silver Nanoparticles in Experimental RSV Infection. Viruses 2019, 11, 732. [CrossRef]

170. Yang, X.X.; Li, C.M.; Huang, C.Z. Curcumin modified silver nanoparticles for highly efficient inhibition of respiratory syncytial virus infection. Nanoscale 2016, 8, 3040-3048. [CrossRef]

171. Rai, M.; Bonde, S.; Yadav, A.; Plekhanova, Y.; Reshetilov, A.; Gupta, I.; Golińska, P.; Pandit, R.; Ingle, A.P. Nanotechnology-based promising strategies for the management of COVID-19: Current development and constraints. Expert Rev. Anti Infect. Ther. 2020, 8, 1-10. [CrossRef]

172. Machado, L.F.; Sanfelice, R.A.; Bosqui, L.R.; Assolini, J.P.; Scandorieiro, S.; Navarro, I.T.; DepieriCataneo, A.H.; Wowk, P.F.; Nakazato, G.; Bordignon, J.; et al. Biogenic silver nanoparticles reduce adherence, infection, and proliferation of toxoplasma gondii RH strain in HeLa cells without inflammatory mediators induction. Exp. Parasitol. 2020, 211, 107853. [CrossRef]

173. Ratan, Z.A.; Haidere, M.F.; Nurunnabi, M.; Shahriar, S.M.; Ahammad, A.J.S.; Shim, Y.Y.; Reaney, M.J.T.; Cho, J.Y. Green Chemistry Synthesis of Silver Nanoparticles and Their Potential Anticancer Effects. Cancers 2020, 12, 855. [CrossRef] [PubMed]

174. Mishra, A.; Mehdi, S.J.; Irshad, M.; Ali, A.; Sardar, M.; Moshahid, M.; Rizvi, A. Effect of biologically synthesized silver nanoparticles on human cancer cells. Sci. Adv. Mater. 2012, 4, 1200-1206. [CrossRef]

175. Gurunathan, S.; Park, J.H.; Han, J.W.; Kim, J.H. Comparative assessment of the apoptotic potential of silver nanoparticles synthesized by Bacillus tequilensis and Calocybe indica in MDA-MB-231 human breast cancer cells: Targeting p53 for anticancer therapy. Int. J. Nanomed. 2015, 10, 4203. [CrossRef] [PubMed]

176. Khanra, K.; Panja, S.; Choudhuri, I.; Chakraborty, A.; Bhattacharyya, N. Evaluation of antibacterial activity and cytotoxicity of green synthesized silver nanoparticles using Scopariadulcis. Nano Biomed. Eng. 2015, 7, 128-133. [CrossRef] 
177. Inbakandan, D.; Kumar, C.; Bavanilatha, M.; Ravindra, D.N.; Kirubagaran, R.; Khan, S.A. Ultrasonic-assisted green synthesis of flower like silver nanocolloids using marine sponge extract and its effect on oral biofilm bacteria and oral cancer cell lines. Microb. Pathog. 2016, 99, 135-141. [CrossRef] [PubMed]

178. Sathishkumar, P.; Preethi, J.; Vijayan, R.; Yusoff, A.R.M.; Ameen, F.; Suresh, S.; Balagurunathan, R.; Palvannan, T. Anti-acne, anti-dandruff and anti-breast cancer efficacy of green synthesised silver nanoparticles using Coriandrum sativum leaf extract. $J$. Photochem. Photobiol. B Biol. 2016, 163, 69-76. [CrossRef]

179. Ovais, M.; Khalil, T.A.; Raza, A.; Khan, M.A.; Ahmad, I.; Islam, N.U.; Saravanan, M.; Ubaid, M.F.; Ali, M.; Shinwari, Z.K. Green synthesis of silver nanoparticles via plant extracts: Beginning a new era in cancer theranostics. Nanomedicine 2016, 11, 3157-3177. [CrossRef]

180. Mousavi, B.; Tafvizi, F.; ZakerBostanabad, S. Green synthesis of silver nanoparticles using Artemisia turcomanica leaf extract and the study of anti-cancer effect and apoptosis induction on gastric cancer cell line (AGS). Artif. Cells Nanomed. Biotechnol. 2018, 46, 499-510. [CrossRef] [PubMed]

181. Mukherjee, S.; Chowdhury, D.; Kotcherlakota, R.; Patra, S.B.V.; Bhadra, M.P.; Sreedhar, B.; Parta, C.R. Potential theranostics application of bio-synthesized silver nanoparticles (4-in-1 system). Theranostics 2014, 4, 316-335. [CrossRef]

182. Gurunathan, S.; Han, J.W.; Eppakayala, V.; Jeyaraj, M.; Kim, J.-H. Cytotoxicity of biologically synthesized silver nanoparticles in MDA-MB-231 human breast cancer cells. Biomed. Res. Int. 2013, 2013, 535796. [CrossRef] [PubMed]

183. Gurunathan, S.; Raman, J.; Malek, S.N.A.; John, P.A.; Vikineswary, S. Green synthesis of silver nanoparticles using Ganoderma neo-japonicum Imazeki: A potential cytotoxic agent against breast cancer cells. Int. J. Nanomed. 2013, 8, 4399-4413. [CrossRef]

184. Gurunathan, S.; Lee, K.J.; Kalishwaralal, K.; Sheikpranbabu, S.; Vaidyanathan, R.; Eom, S.H. Antiangiogenic properties of silver nanoparticles. Biomaterials 2009, 30, 6341-6350. [CrossRef] [PubMed]

185. Baharara, J.; Namvar, F.; Mousavi, M.; Ramezani, T.; Mohamad, R. Anti-Angiogenesis Effect of Biogenic Silver Nanoparticles Synthesized Using Saliva officinalis on Chick Chorioalantoic Membrane (CAM). Molecules 2014, 19, 13498-13508. [CrossRef] [PubMed]

186. Jeyaraj, M.; Sathishkumar, G.; Sivanandhan, G.; MubarakAli, D.; Rajesh, M.; Arun, R. Ganapathi; A. Biogenic silver nanoparticles for cancer treatment: An experimental report. Colloids Surf. B 2013, 106, 86-92. [CrossRef]

187. Salehi, S.; Shandiz, S.A.S.; Ghanbar, F.; Darvish, M.R.; Ardestani, M.S.; Mirzaie, A.; Jafari, M. Phytosynthesis of silver nanoparticles using Artemisia marschalliana Sprengel aerial part extract and assessment of their antioxidant, anticancer, and antibacterial properties. Int. J. Nanomed. 2016, 11, 1835. [CrossRef]

188. Patra, S.; Mukherjee, S.; Barui, A.K.; Ganguly, A.; Sreedhar, B.; Patra, C.R. Green synthesis, characterization of gold and silver nanoparticles and their potential application for cancer therapeutics. Mater. Sci. Eng. C 2015, 53, 298-309. [CrossRef] [PubMed]

189. Kumar, V.; Singh, S.; Srivastava, B.; Bhadouria, R.; Singh, R. Green synthesis of silver nanoparticles using leaf extract of Holoptelea integrifolia and preliminary investigation of its antioxidant, antiinflammatory, antidiabetic and antibacterial activities. J. Environ. Chem. Eng. 2019, 7, 103094. [CrossRef]

190. Ibrahim, S.; Zahoor Ahmad, Z.; Manzoor, M.Z.; Muhammad Mujahid, M.; Faheem, Z.; Adnan, A. Optimization for biogenic microbial synthesis of silver nanoparticles through response surface methodology, characterization, their antimicrobial, antioxidant, and catalytic potential. Sci. Rep. 2021, 11, 770. [CrossRef]

191. Savary, S.; Willocquet, L.; Pethybridge, S.J.; Esker, P.; McRoberts, N.; Nelson, A. The global burden of pathogens and pests on major food crops. Nat. Ecol. Evol. 2019, 3, 430-439. [CrossRef]

192. Arya, A.; Arya, C.; Misra, R. Mechanism of action in arbuscular mycorrhizal symbionts to control fungal diseases. In Management of Fungal Plant Pathogens; Arya, A., Perello, A.E., Eds.; CABI: Wallingford, UK, 2010; pp. 171-182.

193. Medina-Pérez, G.; Fernández-Luqueño, F.; Campos-Montiel, R.G.; Sánchez-López, K.B.; Afanador-Barajas, L.N.; Prince, L. Nanotechnology in crop protection: Status and future trends. In Nano-Biopesticides Today and Future Perspectives; Academic Press: Cambridge, MA, USA, 2019; pp. 17-45. [CrossRef]

194. Jamdagni, P.; Khatri, P.; Rana, J.S. Biogenic synthesis of silver nanoparticles from leaf extract of Elettaria cardamomum and their antifungal activity against phytopathogens. Adv. Mater. Proc. 2018, 3, 129-135. [CrossRef]

195. Elamawi, R.M.; Al-Harbi, R.E. Effect of biosynthesized silver nanoparticles on Fusarium oxysporum fungus the cause of seed rot disease of faba bean, tomato and barley. J. Plant Prot. Pathol. 2014, 5, 225-237. [CrossRef]

196. Win, T.T.; Khan, S.; Fu, P. Fungus-(Alternaria sp.) mediated silver nanoparticles synthesis, characterization, and screening of antifungal activity against some phytopathogens. J. Nanotechnol. 2020, 2020, 8828878. [CrossRef]

197. Mishra, S.; Singh, B.R.; Singh, A.; Keswani, C.; Naqvi, A.H.; Singh, H.B. Biofabricated silver nanoparticles act as a strong fungicide against Bipolarissorokiniana causing spot blotch disease in wheat. PLoS ONE 2014, 9, e97881. [CrossRef] [PubMed]

198. Krishnaraj, C.; Ramachandran, R.; Mohan, K.; Kalaichelvan, P.T. Optimization for rapid synthesis of silver nanoparticles and its effect on phytopathogenic fungi. Spectrochim. Acta Mol. Biomol. Spectrosc. 2012, 93, 95-99. [CrossRef] [PubMed]

199. Heflish, A.A.; Hanfy, A.E.; Ansari, M.J.; Dessoky, E.S.; Attia, A.O.; Elshaer, M.M.; Behiry, S.I. Green biosynthesized silver nanoparticles using Acalypha wilkesiana extract control root-knot nematode. J. King Saud Univ. Sci. 2021, 33, 101516. [CrossRef]

200. Al-Otibi, F.; Perveen, K.; Al-Saif, N.A.; Alharbi, R.I.; Bokhari, N.A.; Albasher, G.; Al-Mosa, M.A. Biosynthesis of silver nanoparticles using Malva parviflora and their antifungal activity. Saudi J. Biol. Sci. 2021 28, 2229-2235. [CrossRef]

201. Sharma, P.; Bhatt, D.; Zaidi, M.G.H.; Saradhi, P.P.; Khanna, P.K.; Arora, S. Silver nanoparticle-mediated enhancement in growth and antioxidant status of Brassica juncea. Appl. Biochem. Biotechnol. 2012, 167, 2225-2233. [CrossRef] 
202. Mehmood, A.; Murtaza, G. Application of SNPs to improve yield of Pisum sativum L. (pea). IET Nanobiotechnol. 2017, 11, 390-394. [CrossRef]

203. Batool, S.U.; Javed, B.; Sohail; Zehra, S.S.; Mashwani, Z.-U.-R.; Raja, N.I.; Khan, T.; ALHaithloul, H.A.S.; Alghanem, S.M.; Al-Mushhin, A.A.M.; et al. Exogenous Applications of Bio-fabricated Silver Nanoparticles to Improve Biochemical, Antioxidant, Fatty Acid and Secondary Metabolite Contents of Sunflower. Nanomaterials 2021, 11, 1750. [CrossRef]

204. Haji Basheerudeen, M.A.; Mushtaq, S.A.; Soundhararajan, R.; Nachimuthu, S.K.; Srinivasan, H. Marine endophytic fungi mediated Silver nanoparticles and their application in plant growth promotion in Vigna radiata L. Int. J. Nano Dimens. 2021, 12, $1-10$.

205. Zhang, H.; Chen, S.; Jia, X.; Huang, Y.; Ji, R.; Zhao, L. Comparation of the phytotoxicity between chemically and green synthesized silver nanoparticles. Sci. Total Environ. 2021, 752, 142264. [CrossRef] [PubMed]

206. Yeleliere, E.; Cobbina, S.J.; Abubakari, Z.I. Review of microbial food contamination and food hygiene in selected capital cities of Ghana. Cogent. Food Agric. 2017, 3, 1395102. [CrossRef]

207. Ravindran, R.E.; Subha, V.; Ilangovan, R. Silver nanoparticles blended PEG/PVA nanocomposites synthesis and characterization for food packaging. Arab. J. Chem. 2020, 13, 6056-6060. [CrossRef]

208. Kowsalya, E.; MosaChristas, K.; Balashanmugam, P.; Manivasagan, V.; Devasena, T.; Jaquline, C.R.I. Sustainable use of biowaste for synthesis of silver nanoparticles and its incorporation into gelatin-based nanocomposite films for antimicrobial food packaging applications. J. Food Process Eng. 2021, 44, e13641. [CrossRef]

209. Ediyilyam, S.; George, B.; Shankar, S.S.; Dennis, T.T.; Wacławek, S.; Černík, M.; Padil, V.V.T. Chitosan/Gelatin/Silver Nanoparticles Composites Films for Biodegradable Food Packaging Applications. Polymers 2021, 13, 1680. [CrossRef] [PubMed]

210. Bhople, S.; Gaikwad, S.; Deshmukh, S.; Bonde, S.; Gade, A.; Sen, S.; Brzezinska, A.; Dahm, H.; Rai, M. Myxobacteria-mediated synthesis of silver nanoparticles and their impregnation in wrapping paper used for enhancing shelf life of apples. IET Nanobiotechnol. 2016, 10, 389-394. [CrossRef] [PubMed]

211. Shastri, J.P.; Rupani, M.G.; Jain, R.L. Antimicrobial activity of nanosilver-coated socks fabrics against foot pathogens. J. Text. Inst. 2012, 103, 1234-1243. [CrossRef]

212. Hasan, K.M.F.; Pervez, M.N.; Talukder, M.E.; Sultana, M.Z.; Mahmud, S.; Meraz, M.M.; Bansal, V.; Genyang, C. A Novel Coloration of Polyester Fabric through Green Silver Nanoparticles (G-AgNPs@PET). Nanomaterials 2019, 9, 569. [CrossRef] [PubMed]

213. Ravindra, S.; Mohan, Y.M.; Reddy, N.N.; Raju, K.M. Fabrication of antibacterial cotton fibres loaded with silver nanoparticles via "Green Approach". Colloids Surf. A Physicochem. Eng. 2010 367, 31-40. [CrossRef]

214. Montes-Hernandez, G.; Di Girolamo, M.; Sarret, G.; Bureau, S.; Fernandez-Martinez, A.; Lelong, C.; EymardVernain, E. In Situ Formation of Silver Nanoparticles (Ag-NPs) onto Textile Fibers. ACS Omega 2021, 6, 1316-1327. [CrossRef]

215. Shateri-Khalilabad, M.; Yazdanshenas, M.E.; Etemadifar, A. Fabricating multifunctional silver nanoparticles-coated cotton fabric. Arab. J. Chem. 2017, 10, S2355-S2362. [CrossRef]

216. Shabbir, M.; Mohammad, F. Multifunctional AgNPs@ Wool: Colored, UV-protective and antioxidant functional textiles. Appl. Nanosci. 2018, 8, 545-555. [CrossRef]

217. Vankar, P.S.; Shukla, D. Biosynthesis of silver nanoparticles using lemon leaves extract and its application for antimicrobial finish on fabric. Appl. Nanosci. 2012, 2, 163-168. [CrossRef]

218. Rehan, M.; Elshemy, N.S.; Haggag, K.; Montaser, A.S.; Ibrahim, G.E. Phytochemicals and volatile compounds of peanut red skin extract: Simultaneous coloration and in situ synthesis of silver nanoparticles for multifunctional viscose fibers. Cellulose 2020, 27, 9893-9912. [CrossRef]

219. Čuk, N.; Šala, M.; Gorjanc, M. Development of antibacterial and UV protective cotton fabrics using plant food waste and alien invasive plant extracts as reducing agents for the in-situ synthesis of silver nanoparticles. Cellulose 2021, 28, 3215-3233. [CrossRef]

220. Arya, G.; Kumari, R.M.; Sharma, N.; Gupta, N.; Kumar, A.; Chatterjee, S.; Nimesh, S. Catalytic, antibacterial and antibiofilm efficacy of biosynthesised silver nanoparticles using Prosopis juliflora leaf extract along with their wound healing potential. J. Photochem. Photobiol. B Biol. 2019, 190, 50-58. [CrossRef] [PubMed]

221. David, L.; Moldovan, B. Green Synthesis of Biogenic Silver Nanoparticles for Efficient Catalytic Removal of Harmful Organic Dyes. Nanomaterials 2020, 10, 202. [CrossRef] [PubMed]

222. Saha, P.; Mahiuddin, M.; Nazmul Islam, A.B.M.; Ochiai, B. Biogenic synthesis and catalyticefficacy of silver nanoparticles based on peel extracts of Citrusma croptera fruit. ACS Omega 2021, 6, 18260-18268. [CrossRef] [PubMed]

223. Wani, I.A. Recent advances in biogenic silver nanoparticles and nano composite based plasmonic-colorimetric and electrochemical sensors. ECS J. Solid State Sci. Technol. 2021, 10, 047003. [CrossRef]

224. Hoyos, L.E.S.D.; Sánchez-Mendieta, V.; Vilchis-Nestor, A.R.; Camacho-López, M.A. Biogenic silver nanoparticles as sensors of $\mathrm{Cu}^{2+}$ and $\mathrm{Pb}^{2+}$ in aqueous solutions. Univ. J. Mater. Sci. 2017, 5, 29-37. [CrossRef]

225. Al-Thabaiti, S.A.; Khan, Z. Biogenic synthesis of silver nanoparticles, sensing and photo catalytic activities for bromothymol blue. J. Photochem. Photobiol. 2020, 3-4, 100010. [CrossRef]

226. Hussain, M.; Nafady, A.; Sirajuddin; Avc1, A.; Pehlivan, E.; Nisar, J.; Sherazi, S.T.H.; Balouch, A.; Shah, M.R.; Almaghrabi, O.A.; et al. Biogenic silver nanoparticles for trace colorimetric sensing of enzyme disrupter fungicide vinclozolin. Nanomaterials 2019, 9 , 1604. [CrossRef] [PubMed] 
227. Tagad, C.K.; Dugasani, S.R.; Aiyer, R.; Park, S.; Kulkarni, A.; Sabharwal, S. Green synthesis of silver nanoparticles and their application for the development of optical fiber based hydrogen peroxide sensor. Sens. Actuators B Chem. 2013, 183, 144-149. [CrossRef]

228. Khan, M.Z.H.; Tarek, F.K.; Nuzat, M.; Momin, M.A.; Hasan, M.R. Rapid biological synthesis of silver nanoparticles from Ocimum sanctum and their characterization. J. Nanosci. 2017, 2017, 1693416. [CrossRef]

229. Ahmed, S.; Saifullah; Ahmad, M.; Swami, B.L.; Ikram, S. Green synthesis of silver nanoparticles using Azadirachta indica aqueous leaf extract. J. Radiat. Res. Appl. Sci. 2016, 9, 1-7. [CrossRef]

230. Akter, M.; Sikder, T.; Rahman, M.; Ullah, A.K.M.A.; Hossain, K.F.B.; Banik, S.; Hosokawa, T.; Saito, T.; Kurasaki, M. A systematic review on silver nanoparticles-induced cytotoxicity: Physicochemical properties and perspectives. J. Adv. Res. 2018, 9, 1-16. [CrossRef] [PubMed]

231. Ferdous, Z.; Nemmar, A. Health Impact of Silver Nanoparticles: A Review of the Biodistribution and Toxicity Following Various Routes of Exposure. Int. J. Mol. Sci. 2020, 21, 2375. [CrossRef]

232. Dong, L.; Lai, Y.; Zhou, H.; Yan, B.; Liu, J. The biodistribution and transformation of nanoparticulate and ionic silver in rat organs in vivo. NanoImpact 2020, 20, 100265. [CrossRef]

233. Keat, C.L.; Aziz, A.; Eid, A.M.; Elmarzugi, N.A. Biosynthesis of nanoparticles and silver nanoparticles. Bioresour. Bioprocess. 2015, 2, 47. [CrossRef]

234. Sung, J.H.; Ji, J.H.; Yoon, J.U.; Kim, D.S.; Song, M.Y.; Jeong, J.; Han, B.S.; Han, J.H.; Chung, Y.H.; Kim, J. Lung function changes in Sprague-Dawley rats after prolonged inhalation exposure to silver nanoparticles. Inhal. Toxicol. 2008, 20, 567-574. [CrossRef] [PubMed]

235. Yang, L.; Kuang, H.; Zhang, W.; Aguilar, Z.P.; Wei, H.; Xu, H. Comparisons of the biodistribution and toxicological examinations after repeated intravenous administration of silver and gold nanoparticles in mice. Sci. Rep. 2017, 7, 3303. [CrossRef] [PubMed]

236. Dziendzikowska, K.; Gromadzka-Ostrowska, J.; Lankoff, A.; Oczkowski, M.; Krawczyńska, A.; Chwastowska, J.; SadowskaBratek, M.; Chajduk, E.; Wojewódzka, M.; Dušinská, M.; et al. Time-dependent biodistribution and excretion of silver nanoparticles in male Wistar rats. J. Appl. Toxicol. 2012, 32, 920-928. [CrossRef] [PubMed]

237. Zande, V.M.; Vandebriel, R.J.; van Doren, E.; Kramer, E.; Herrera Rivera, Z.; Serrano-Rojero, C.S.; Gremmer, E.R.; Mast, J.; Peters, R.J.B.; Hollman, P.C.G.; et al. Distribution, Elimination, and Toxicity of Silver Nanoparticles and Silver Ions in Rats after 28-Day Oral Exposure. ACS Nano 2012, 6, 7427-7442. [CrossRef]

238. Panda, K.K.; Achary, V.M.M.; Krishnaveni, R.; Padhi, B.K.; Sarangi, S.N.; Sahu, S.N.; Panda, B.B. In vitro biosynthesis and genotoxicity bioassay of silver nanoparticles using plants. Toxicol. In Vitro 2011, 25, 1097-1105. [CrossRef] [PubMed]

239. Pannerselvam, B.; Thiyagarajan, D.; Pazhani, A.; Thangavelu, K.P.; Kim, H.J.; Rangarajulu, S.K. Copperpod Plant Synthesized AgNPs Enhance Cytotoxic and Apoptotic Effect in Cancer Cell Lines. Processes 2021, 9, 888. [CrossRef]

240. Ashajyothia, C.; Chandrakanth, R.K. A pilot toxicology study of biogenic silver nanoparticles: In vivo by intraperitoneal and intravenous infusion routes in rats. J. Exp. Nanosci. 2019, 14, 89-106. [CrossRef]

241. Lima, R.; Seabra, A.B.; Durán, N. Silver nanoparticles: A brief review of cytotoxicity and genotoxicity of chemically and biogenically synthesized nanoparticles. J. Appl. Toxicol. 2012, 32, 867-879. [CrossRef] [PubMed]

242. Arunachalam, K.D.; Arun, L.B.; Annamalai, S.K.; Arunachalam, A.M. Potential anticancer properties of bioactive compounds of Gymnema sylvestre and its biofunctionalized silver nanoparticle. Int. J. Nanomed. 2015, 10, 31-41. [CrossRef]

243. El-Naggar, N.E.-A.; Hussein, M.H.; El-Sawah, A.A. Bio-fabrication of silver nanoparticles by phycocyanin, characterization, in vitro anticancer activity against breast cancer cell line and in vivo cytotoxicity. Sci. Rep. 2017, 7, 10844-10864. [CrossRef]

244. Ansar, S.; Tabassum, H.; Aladwan, N.S.M.; Ali, M.N.; Almaarik, B.; AlMahrouqi, S.; Abudawood, M.; Banu, N.; Alsubki, R. Ecofriendly silver nanoparticles synthesis by Brassica oleracea and its antibacterial, anticancer and antioxidant properties. Sci. Rep. 2020, 10, 18564. [CrossRef]

245. Hamida, R.S.; Abdelmeguid, N.E.; Ali, M.A.; Bin-Meferij, M.M.; Khalil, M.I. Synthesis of silver nanoparticles using a novel cyanobacteria Desertifilum sp. extract: Their antibacterial and cytotoxicity effects. Int. J. Nanomed. 2020, 15, 49-63. [CrossRef] [PubMed]

246. Recordati, C.; De Maglie, M.; Bianchessi, S.; Argentiere, S.; Cella, C.; Mattiello, S.; Cubadda, F.; Aureli, F.; D’Amato, M.; Raggi, A. Tissue distribution and acute toxicity of silver after single intravenous administration in mice: Nano-specific and size-dependent effects. Part. Fibre Toxicol. 2016, 13, 12. [CrossRef] [PubMed]

247. Netala, V.R.; Bethu, M.S.; Pushpalatha, B. Biogenesis of silver nanoparticles using endophytic fungus Pestalotiopsis microspora and evaluation of their antioxidant and anticancer activities. Int. J. Nanomed. 2016, 11, 5683. [CrossRef] [PubMed]

248. Szerencsés, B.; Igaz, N.; Tóbiás, A.; Prucsi, Z.; Rónavári, A.; Bélteky, P.; Madarász, D.; Papp, C.; Makra, I.; Vágvölgyi, C.; et al. Size-dependent activity of silver nanoparticles on the morphological switch and biofilm formation of opportunistic pathogenic yeasts. BMC Microbiol. 2020, 20, 176. [CrossRef]

249. Gopinath, V.S.; Arunkumar, J.; Marsili, E.; MubarakAlie, F.; Velusamya, P.; Vadivelu, J. Biogenic synthesis, characterization of antibacterial silver nanoparticles and its cell cytotoxicity. Arabian J. Chem. 2017, 10, 1107-1117. [CrossRef]

250. Ballotin, D.; Fulaz, S.; Souza, M.L.; Corio, P.; Rodrigues, A.G.; Souza, A.O. Elucidating protein involvement in the stabilization of the biogenic silver nanoparticles. Nanoscale Res. Lett. 2016, 11, 313. [CrossRef] 